University of Wisconsin Milwaukee

UWM Digital Commons

Theses and Dissertations

August 2013

\title{
Parents' Treatment of Their Children's Pain at Home: Pharmacological and Non- Pharmacological Approaches
}

Ayala Y. Gorodzinsky

University of Wisconsin-Milwaukee

Follow this and additional works at: https://dc.uwm.edu/etd

Part of the Clinical Psychology Commons, and the Health Services Administration Commons

\section{Recommended Citation}

Gorodzinsky, Ayala Y., "Parents' Treatment of Their Children's Pain at Home: Pharmacological and Non-Pharmacological Approaches" (2013). Theses and Dissertations. 8.

https://dc.uwm.edu/etd/8

This Dissertation is brought to you for free and open access by UWM Digital Commons. It has been accepted for inclusion in Theses and Dissertations by an authorized administrator of UWM Digital Commons. For more information, please contact open-access@uwm.edu. 
PARENTS' TREATMENT OF THEIR CHILDREN'S PAIN AT HOME:

PHARMACOLOGICAL AND NON-PHARMACOLOGICAL APPROACHES

by

Ayala Y. Gorodzinsky

A Dissertation Submitted in

Partial Fulfillment of the

Requirements for the Degree of

Doctor of Philosophy

in Psychology

at

The University of Wisconsin-Milwaukee

August 2013 


\begin{abstract}
PARENTS' TREATMENT OF THEIR CHILDREN'S PAIN AT HOME: PHARMACOLOGICAL AND NON-PHARMACOLOGICAL APPROACHES
\end{abstract}

by

\author{
Ayala Y. Gorodzinsky \\ The University of Wisconsin-Milwaukee, 2013 \\ Under the Supervision of W. Hobart Davies
}

During childhood, individuals often experience pain on a daily or nearly daily basis (American Academy of Pediatrics and American Pain Society, 2001). Pain can be treated using pharmacological or non-pharmacological techniques. This study will focus on the techniques provided by parents, since parents most often treat children's painful experiences at home (Finley, McGrath, Forward, McNeill \& Fitzgerald, 1996). The processes involved in parental decision-making regarding which techniques to use include a combination demographic, availability and perceived need factors (Andersen, 1995). Seven hundred and fifty-six parents of children 6 to 17 years completed a survey regarding use and effectiveness of pharmacological and non-pharmacological techniques to alleviate pain at home, pain catastrophizing, and questions regarding dialogue with health care providers about pain alleviation techniques. Parents' use of different techniques varied due to many factors. Parents used fewer pharmacological techniques with increased worry regarding pain medications, more pharmacological techniques with increased pain catastrophizing, and fewer non-pharmacological techniques as child's age increases. Child self-administration of pain alleviation techniques increased with child's age. Parents were more likely to have spoken with their healthcare provider about 
pharmacological techniques than non-pharmacological techniques. This study provides information that can help providers initiate conversations and education regarding treatment options, and align recommendations for pain management with techniques that parents are likely to be using or providing alternative recommendations with more detailed instructions and support. 
(c) Copyright by Ayala Y. Gorodzinsky

All Rights Reserved 
I first thank my advisor, W. Hobart Davies, for his support and continued enthusiasm while working on this project. I am grateful to my other committee members, Bonnie Klein-Tasman, Katie Mosack, Robyn Ridley and Anthony Hains for their feedback and encouragement. I also thank all the members of the Child Stress and Coping Lab for creating such a supportive and enjoyable environment. I am grateful to the trainee and mentor members of the Pain in Child Health Initiative for their encouragement and passion for childhood pain research. I thank the participants without whom this research would not have been possible. I also have a special and deep appreciation to my family and friends for their encouragement, enduring support and acceptance. 


\section{TABLE OF CONTENTS}

Introduction

Pain Experiences in Childhood

Types of Pain Treatment $\quad 4$

Andersen's Sociobehavioral Model

Enabling Factor: Parents' Awareness and Use of Pharmacological Treatment of Child's

Pain

Enabling Factor: Decisions Regarding Pharmacological Treatment of Pain in

Childhood

Enabling Factor: Parents' Non-pharmacological Treatment of Childhood Pain

Enabling Factor: Decisions about Treatment Options

Enabling Factor: Conversations with Healthcare Providers

Predisposing Factor: Developmental Changes Influencing Treatment Choice __ 22

Needs Factor: Parents' Level of Pain Catastrophizing __ 24

Needs Factor: Children's Expression of Pain 227

Limitations of Current Literature and Future Directions___ 28

Current Study__ 31

Hypotheses_ 32

Method__ 35

Participants_ 35

Procedure 35

Measures 36

Data Analyses__ 37

Results

Discussion $\quad 44$

Needs Factors Influencing Parents' Decisions of Pain Alleviation Treatments___ 44

Predisposing Factors Influencing Parents' Decisions of Pain Alleviation Treatments_ 45

Enabling Factors Influencing Parents' Decisions of Pain Alleviation Treatments__ 47

Study Limitations $\quad 49$

Future Research 50

Conclusions and Implications ___ 53

References 


\section{Figures}

Figure 1. Types of pain treatments and providers 65

Figure 2. Modified Andersen's sociobehavioral model

Figure 3. Trends in use of self-administration of pharmacological techniques based on children's

age

Figure 4. Trends in use of self-administration of non-pharmacological techniques based on children's age

Figure 5. Proposed model for current factors leading to parents' treatment decisions for childhood pain at home

Figure 6. Proposed model for future factors leading to parents' treatment decisions and reduced oliganalgesia and increased effective treatment of childhood pain at home 
Tables

Table 1. Frequency of Children's Pain Experiences

Table 2. Children's Pain Locations

Table 3. Non-pharmacological Techniques Provided

73

Table 4. Descriptive Statistics of Children's Age Categories for Higher Frequency Pain

Group 
Appendix

Relevant SurveyMonkey.com Questions 


\section{Introduction}

Pain is a common experience, with children often having a painful experience at least once a day. These painful experiences can result from regular childhood activities, illness and medical procedures (American Academy of Pediatrics and American Pain Society (AAP \& APS), 2001; Moon, Chambers, Larochette, Hayton, Craig \& McGrath, 2008). Relief of painful experiences can be provided using pharmacological or nonpharmacological techniques, which are provided by professionals, by parents or selfadministered. According to the literature, children's perceptions of pain treatment are influenced by learning behaviors from parents, such as parental modeling of treatment use, reinforcement of pain symptoms (Palermo \& Chambers, 2005) and catastrophizing about pain symptoms (Sullivan et al., 2001).

Parents' decisions regarding which techniques to use to alleviate pain, their own and their children's, can be assessed using a modified version of Andersen's sociobehavioral model (Robinson, Lorenc, \& Blair, 2009). This model has gone through several iterations; however, all versions focus on factors leading to healthcare utilization decisions. In the model, the relevant factors for parents' use of pain alleviation techniques at home include predisposing factors (such as sociodemographics), enabling factors (such as access to healthcare), need factors (including subjective experience of pain), and outcomes (such as satisfaction with techniques used) (Andersen, 1995; Robinson et al., 2009). All of these factors, which will be explored in more detail below, are relevant when parents are deciding which treatment to provide for their child experiencing pain. Notably, pain treatment options divide into two major categories: pharmacological and non-pharmacological; and this sociobehavioral model can be used to assess decisions 
regarding both pharmacological and non-pharmacological types of treatment techniques (Kelner \& Wellman, 1997; Upchurch et al., 2008).

To date, most of the literature regarding treatment of children's pain experiences has come from professionally-provided pain management, chronic pain or post-operative populations. The new perspective offered by the current study is the focus on the everyday pain experiences of children and adolescents treated at home by their parents. The value of this study arises specifically because it has been noted that most of the pain experienced by children is treated by parents at home (Finley, McGrath, Forward, McNeil \& Fitzgerald, 1996). The current study provides additional information for health care providers regarding the techniques used by parents, with or without provider consultation, to alleviate their children's pain experiences at home. An understanding of the techniques used by parents at home will continue to elucidate the most influential avenues for further communication between providers and patients, in the hopes of increasing appropriate and adequate treatment of children's pain experiences.

The introduction of this paper will provide information regarding childhood pain experiences including a review of the types of pain experienced and available treatment techniques used to alleviate pain. Second, Andersen's sociobehavioral model regarding factors influencing treatment decisions will be explained. Third, relevant factors from Andersen's sociobehavioral model will be expanded on, specifically those regarding parents' treatment of their children's pain at home. Fourth, limitations of the available literature and future directions will be presented. Finally, the current study will be outlined as one approach to begin addressing the limitations of the current knowledge base. 


\section{Pain Experiences in Childhood}

Children often experience some sort of pain on a daily basis (Craig, Lilley \& Gilbert, 1996), with these pain experiences including bumps and bruises from regular childhood activities, pain associated with illness and pain associated with medical procedures (AAP \& APS, 2001). Between 30 to $40 \%$ of children complain about a painful symptom at least once a week (Palermo, 2000). Pain can be divided into chronic and acute pain. Chronic pain refers to pain that persists for three or more months (Palermo, 2000), and acute pain is pain that occurs as a direct response to an injury or tissue damage (AAP \& APS, 2001). In contrast to the experience of chronic pain, children more commonly experience acute or everyday pain (Koller, Myers, Lorenz \& Godambe, 2007), with prevalence rates exceeding $50 \%$ in some community samples (Perquin et al., 2000).

Pain is a subjective experience, and is therefore difficult to address using the same treatment for all individuals. The International Association for the Study of Pain Subcommittee on Taxonomy (1979) has provided a definition of pain which addresses the subjectivity of the experience by stating that pain is "an unpleasant sensory and emotional experience connected with actual or potential tissue damage, or described in terms of such damage" (p. 250). By including the emotional component of pain, this definition highlights the importance of effective and prompt treatment of pain since the emotional experience associated with pain can become overwhelming if the pain is not treated effectively (Schecter, 1989).

In 1989, Wilson and Pendleton coined the term oligoanalgesia, which refers to the under-treatment of pain. This term emerged due to recognition that children's pain was 
not consistently being treated and concern grew given the potential negative long-term sensory (such as increased sensitivity to stimuli) and emotional experiences (such as increased anxiety surrounding future pain experiences), which may arise from under- or un-treated pain (Ducharme, 2000). Oligoanalgesia remains a major concern in childhood as several barriers related to the assessment and treatment of pain (described below) continue to linger in the field of health care and among parents, despite strong research evidence to the contrary (Mathews, 2011).

\section{Types of Pain Treatment}

Effective pain management involves accurate selection of the most appropriate treatment technique. There are two main categories of treatments for pain: pharmacological and non-pharmacological (see Figure 1). Pharmacological treatment techniques refer to those that involve pharmaceutical medications and are attributed to Western medicine. Non-pharmacological techniques often overlap with the techniques that fall under the category of complementary and alternative medicine (CAM), such that all these techniques refer to those that do not involve either topical or ingested pharmaceutical medication. However, it is difficult to clearly distinguish between CAM and non-pharmacological techniques (Sirois, 1998), since many of the techniques overlap between these two categories. A simple distinction is that CAM techniques can be professionally provided treatments, such as acupuncture, homeopathy and massage; whereas, a large portion of non-pharmacological techniques can be self-administered such as thermo-compresses, baths and herbal teas. For example, massage can be categorized as CAM and non-pharmacological as it does not involve ingestion of pharmaceutical medication. However, it is categorized under the CAM technique when 
provided by a massage therapist and under the non-pharmacological technique categorization when provided by a non-professional such as a parent. The focus of this study is on non-pharmacological techniques provided by parents at home.

Pharmacological techniques are often just referred to as medications. Medications used to treat pain are referred to as analgesics. There are two broad categories of analgesics: opioids and non-opioids. Non-opioids, also known as simple analgesics, are viewed as appropriate medications for mild to moderate pain as these analgesics can alleviate low levels of pain with minimal side effects. Non-opioids include acetylsalicylic acid (ASA) (which is effective but infrequently recommended by pediatricians; Drake \& Hain, 2006), acetaminophen and non-steroidal anti-inflammatory drugs (NSAIDs) (Drake \& Hain, 2006; Friedrichsdorf \& Kang, 2007). Opioids are divided into strong/major (high levels of side effects) and minor (lower levels of side effects). Commonly known opioids include codeine, tramadol, and morphine (Drake \& Hain, 2006).

Side effects of analgesics vary as a function of the specific medication being used and can include nausea/vomiting, constipation, pruritus (itching sensation), sedation, agitation (particularly in young children), myoclonus (involuntary muscle contraction), urinary retention, respiratory depression and physiological dependence, tolerance and addiction (Drake \& Hain, 2006). Notably, the combination of physiological dependence, tolerance and addiction is not the same as psychological dependence and addiction. Physiological dependence, tolerance and addiction can be minimized and treated by slowly reducing the dosage so that a child's body becomes accustomed to not having analgesic effects to cope with the pain (Drake \& Hain, 2006; Morton, 1998).

Psychological dependence and addiction have multiple factors, which can influence the 
desire to ingest analgesics and are beyond the physical sensations of pain reduction (Ducharme, 2000). Concerns regarding the adverse side effects of analgesics, specifically addiction, are often misdirected and can lead to under-treatment of pain (AAP \& APS, 2001; Mathews, 2011),

In contrast to straightforward categorization of pharmacological techniques, there are multiple taxonomies presented in the literature regarding the division of nonpharmacological techniques into categories. One taxonomy divides non-pharmacological techniques into physical, cognitive behavioral and active coping techniques. Physical techniques include cuddling, hugs, massage, comfort positioning, and hot and cold compress. Cognitive behavioral techniques include guided imagery, hypnosis, abdominal breathing, distraction, and storytelling. Active coping such as talking about distress and the procedure related to the pain can also reduce pain sensations (Friedrichsdorf \& Kang, 2007; McGrath, 1990; Pain Management Guideline Panel, 1992). Another theory divides complementary techniques used to alleviate pain in the acute pediatric pain population into six categories: comfort, distraction, suggestion, guided imagery, progressive muscle relaxation and hypnosis. A third and commonly used taxonomy presented by Pölkki and colleagues in 2001 states that non-pharmacological techniques can be divided into five categories: 1) cognitive behavioral techniques such as imagery, distraction, and breathing, 2) physical techniques including positioning, thermal regulation, massage and transcutaneous electrical nerve stimulation (TENS), 3) emotional support including touch and comforting, 4) helping with daily activities and 5) creating a comfortable environment (Idvall, Holm \& Runeson, 2005; Pölkki, Vehviläinen-Julkunen \& Pietilä, 2001). 
According to many researchers and health care professionals, the mechanisms of effectiveness for how non-pharmacological techniques alleviate pain are unclear. However, these techniques are helpful to reduce distress and anxiety (Pain Management Guideline Panel, 1992; Young, 2005), and reduction in distress and anxiety levels associated to the experiences of pain is thought to provide individuals with some relief from the pain experience (Helmrich et al., 2001). There is limited research assessing parental selection of pharmacological and non-pharmacological techniques for children's pain. There is however, available information exploring factors influencing individuals' decision-making regarding pain alleviation treatments.

\section{Andersen's Sociobehavioral Model}

The model of healthcare utilization proposed by Andersen and colleagues (Andersen, 1968, 1995; Andersen and Newman, 1973) is the most commonly used model to assess individuals' decisions about healthcare use (Lorenc, Ilan-Clarke, Robinson \& Blair, 2009; Phillips, Morrison, Andersen \& Aday, 1998). This model is most often used to assess decisions about conventional medicine, however it has been used effectively to assess decisions about CAM techniques as well (Kelner \& Wellman, 1997; Upchurch et al., 2008). This model is valuable in assessing factors that influence individuals' decisions regarding healthcare use since it includes both subjective and objective factors (Lorenc et al., 2009). The original model as presented by Andersen (1968) has gone through several revisions, with the original three individual determinants of predisposing factors, enabling factors, and perceived illness level. Predisposing factors most often referred to within this model are demographic features such as gender, age and income (Kelner \& Wellman, 1997; Sirois \& Gick, 2002), as well as individuals’ beliefs about 
healthcare and illness (Andersen \& Newman, 1973; Upchurch et al., 2008). Enabling factors are individual factors that provide individuals with the interest to utilize healthcare resources, such as knowledge of resources and treatment options and ability to access the resources and treatments (Andersen \& Newman, 1973; Kelner \& Wellman, 1997, Upchurch et al., 2008). Perceived illness level, or needs factors, refers to the individual's perceived severity of illness or discomfort due to symptoms (Sirois \& Gick, 2002; Upchurch et al., 2008). The revised versions of the model include also societal determinants, such as technology and norms of the community, and community-based health services system, such as resources available and organization of the resources (Andersen \& Newman, 1973). The newer versions of the model also include a feedback loop between the chosen healthcare techniques and the perceptions of the effectiveness of these techniques as a factor leading to the decision of using the techniques again in the future (Andersen, 1995; Phillips et al., 1998). This feedback loop can be especially important when making decisions about treatments used at home since these techniques are not prescribed and are based solely on parental and child perceptions of the effectiveness and availability of treatment.

A modified version of this model will be presented in this paper to explain the factors that can influence parents' decisions regarding use of pharmacological and nonpharmacological techniques to treat their children's pain at home (See Figure 2). This model can be used to assess the influences that lead parents to decide which treatment techniques to use for their children's pain at home. The overarching decision is whether to use pharmacological or non-pharmacological techniques and within this decision which technique to use. The outcomes of the chosen techniques can influence future 
decisions regarding pain reduction. The sociobehavioral model has been used to assess factors, which influence decisions regarding both conventional/pharmacological and CAM/non-pharmacological techniques.

\section{Enabling Factor: Parents' Awareness and Use of Pharmacological Treatment of Child's Pain}

To date, most of the research conducted assessing pain treatment in children has focused on post-operative pain and in-hospital treatment. Despite the great importance of increasing the effectiveness of children's pain experiences in hospital, most childhood pain experiences occur outside the hospital and are treated by parents at home and not by medical professionals (Finley et al., 1996; Forward, Brown \& McGrath, 1996; GedalyDuff \& Ziebarth, 1994; Maiman, Becker \& Katlic, 1986; Neill, 2000; Pachter, Sumner, Fontan, Sneed \& Bernstein, 1998). Therefore, it is of great importance to understand how parents are treating their children's everyday pain at home. Among the most important components of pain management by analgesics is the administration of effective doses, thus enabling pain reduction with minimal or no side effects and reducing the possibility of experiencing side effects while having no reduction in pain (AAP \& APS, 2001), as can occur when insufficient doses of analgesics are administered (McCracken, Hoskins \& Eccleston, 2006).

The recent development of increased structure for assessment and treatment of childhood pain has led to the World Health Organization's (WHO) creation of recommendations to promote effective treatment of childhood pain. The WHO recommends that medication be provided to children based on 1) the ladder from nonopioids to strong opioids, 2) the regular schedule of administration to ensure a steady 
blood concentration of medication (Pain Management Guideline Panel, 1992), 3) the appropriate route using the least invasive route of administration and 4) the development of an individualized treatment for the child's pain and response to treatment (Drake \& Hain, 2006). Despite the available guidelines for the administration of analgesics for children in pain, multiple researchers have observed that oligoanalgesia is still very prevalent for children. Researchers noted in a retrospective chart review study assessing use of analgesics in the emergency department that only $52.9 \%$ of the children who reported severe pain, as recorded in their medical record, received any analgesic medication (Drendel, Brousseau \& Gorelick, 2006). In a study assessing parents' provision of analgesics to their children following tonsillectomy, though most of the children were experiencing post-operative moderate to severe pain, less than half of the children were receiving pain medications (Wilson \& Helgadóttir, 2006). This oligoanalgesia was due to multiple factors, one of which was parents' perception of the medications and their potential benefits and risks.

Parents use various types of medications to alleviate symptoms of illness at home, and the use of non-prescription medications, also known as over-the-counter (OTC) medications, has been previously assessed. Researchers have estimated that $70 \%$ of health complaints in the United States are treated with OTC medications. In a review study investigating British parents' treatment of their children's acute illnesses at home, researchers found that parents reported they were most likely to begin treatment of their children's illness on their own, and this treatment most often incorporated providing the children with OTC medications (Neill, 2000). The most common OTC medications reported by parents were analgesics, antipyretics (medications that reduce fever) and 
cough medicines. Parents reported using OTC medications and seeking help from family, friends and pharmacists prior to calling the doctor because they did not want to 'bother the doctor'. Factors leading to the decision of calling the doctor for assistance were abnormal symptoms, behavioral changes, perceived increased severity of illness, when parents' attempts to treat the illness failed, and feelings of helplessness or of being unable to cope with illness. Parents reported wanting the doctor to provide reassurance that the treatment the parents provided was the best they could do, to provide information about their child's illness, and to respect the parents' view of the illness and parenting competence. Very few of these parents called the doctor with the intention of acquiring prescription medications for their child (Neill, 2000).

\section{Enabling Factor: Decisions Regarding Pharmacological Treatment of Pain in}

\section{Childhood}

Despite advances in strategies for treating pain in children, there are several barriers that result in continued oligoanalgesia in childhood. These barriers include: 1) the belief that children do not experience pain the same way adults do (Craig et al., 1996; Kankkunen, Vehviläinen-Julkunen \& Pietilä, 2002; Mathews, 2011), 2) the belief that there is no way to conceptualize pain due to the subjective nature of pain experiences (Rolland, 1994), 3) the belief that treating pain in children is not worth the effort since children will have no memory of their pain experience later in life (Mathews, 2011), 4) misplaced concerns regarding the adverse side effects of medications including addiction (AAP \& APS, 2001; Mathews, 2011; McCracken et al., 2006), 5) lack of knowledge about the effective use of opioids, 6) concerns from the physicians about what others (parents and physicians) will think if child is prescribed too many pain medications, 7) 
the belief that nothing can be done about the pain (McCracken et al., 2006) and 8) that pain is a good thing for children to experience (McGrath, 1996; Walco, Cassidy \& Schecter, 1991).

These beliefs and barriers often lead to under-treatment or no treatment of pain, and oligoanalgesia has been noted to have no positive long-term effects. In fact, oligoanalgesia is related to some negative long-term effects in children, including anticipatory and increased pain reactions (Taddio, Shah, Gilbert-MacLeod \& Katz, 2002), as well as increased physiological reactions and negative emotional reactions to later pain experiences (Blount, Piira, Cohen \& Cheng, 2006). The research regarding short-term and long-term negative effects of oligoanalgesia has been conducted mostly in the preterm and infant populations (Blount et al., 2006; Taddio et al., 2002), however pediatric providers now generally accept that oligoanalgesia is not positive for children and infants to experience.

Related to the barriers reported above, those specifically reported by parents using non-pharmacological techniques to alleviate their pre-school children's post-operative pain include that using medication indicates failure of other potential treatments, opioids are too strong for children, distress about potential side effects, and apprehension about addiction (Kankkunen, Vehviläinen-Julkunen, Pietilä, Kokki \& Halonen, 2003c). In this population of parents, fathers were found to be more likely than mothers to believe that analgesics have dangerous effects for their children (Kankkunen et al., 2003c). Parents, whose school-age children had recently undergone tonsillectomy, reported that they might not have given their children pain medication because they believed that children need to learn to cope with difficult situations, such as pain, or because they might have 
been concerned that their children would learn to use drugs to cope with problems (Idvall et al., 2005). These concerns about addiction have been assessed and there is minimal evidence to support development of tolerance or addiction to acetaminophen (Forward et al., 1996). Specifically, the psychological component of drug addiction is often not present for children recovering from surgery (Craig et al., 1996; Pain Management Guideline Panel, 1992).

In response to these barriers and beliefs commonly held by parents regarding use of medications for children's pain, researchers have assessed parents' perceptions of medications in comparison to their provision of medications to children. In these studies, researchers found that despite most parents reporting that they agreed that analgesics could be used for children without much worry and that it was safe to give children the recommended dosage, parents often do not provide the medications as prescribed (Finley et al., 1996; Kankkunen et al., 2002; Rony, Fortier, Chorney, Perret \& Kain, 2010), believed that medications worked best if used as little as possible (Finley et al., 1996; Rony et al., 2010), if saved for when pain was severe (Forward et al., 1996), and had concerns about addiction and severe side effects (Rony et al., 2010). As well, mothers providing treatment for post-operative pain were likely to extend the time between doses of medication when a child was experiencing post-operative pain (Gedaly-Duff \& Ziebarth, 1994). The results from these studies imply that parents may be inadvertently under-medicating. Providing medications ineffectively can be very detrimental for the children, as they may experience the negative side effects, such as nausea and constipation, without receiving as much pain relief as possible from the medications (McCracken et al., 2006). 
A study assessing parents' perceptions of pain control after their child was in the emergency department, due to a fracture, found that parents reported reduced pain management for the following reasons: limited knowledge about the pharmacology of the medication, concerns about drug addiction and concerns that a child taking medication would reduce the accuracy of diagnostic assessment. Researchers have reported that even when parents were given analgesic prescriptions and were instructed to provide their children with medication after a visit to the emergency department, some parents $(26 \%)$ provided their children with a medication other than the one prescribed (Drendel, Lyon, Bergholte \& Kim, 2006). This pattern may be attributed to their concerns about the strength and side effects of the prescribed medication.

In contrast to analgesics prescribed by health care providers, in a study assessing parents' perceptions of OTC medications for their children, it was found that many parents were unaware of any side effects from OTC medications. The authors suggest that the participants in their study believed that anything sold without a prescription is safe for their children. Parents in this study were also unaware of their children's current weight, which is important information since medication dosages are based on children's weight (Birchley \& Conroy, 2002). The results of all these studies indicate that parents may benefit from more direct information regarding dosages of common OTC medications that they are likely providing to their children at home on a regular basis without consultation with a medical professional.

In other studies assessing the use of OTC medications at home, researchers have found that the most common OTC medications were analgesics (Cantrill, Johannesson, Nicolson \& Noyce, 1996), and the most commonly provided analgesic is acetaminophen 
(Simon \& Weinkle, 1997). As with the study by Neill (2000), parents tended to make treatment decisions on their own without consulting a medical provider (Cantrill et al., 1996). However, there is concern about parents providing medications without medical consultation. In another study assessing use of OTC medications, parents were provided with mock dosing vignettes of medications for their children. Many participants (86\%) were able to properly determine the dosing interval of between 4 to 6 hours for their children; however only $40 \%$ provided the correct dosage based on weight for their child (Simon \& Weinkle, 1997). These studies provide information regarding the decisions through which parents progress when treating their children's physical symptoms of illness. As well, the studies provide valuable information regarding parents' hesitance to contacting medical providers.

\section{Enabling Factor: Parents' Non-pharmacological Treatment of Childhood Pain}

As noted above, CAM and non-pharmacological techniques tend to overlap in their categorization. Currently, there is no literature regarding parents' use of CAM or non-pharmacological techniques to treat their children's non-post-operative pain.

Therefore, a summary of CAM and non-pharmacological techniques used by parents to alleviate their children's post-operative pain will be presented. The lack of literature regarding the use of these techniques at home elucidates the importance of studying these patterns of use to further reduce oligoanalgesia for children.

Though most CAM techniques to relieve pain are not novel techniques, the use of these techniques has become more prominent in the past twenty years. For example, individuals in the United States were spending upwards of $\$ 12.8$ billion out of pocket for alternative techniques in 1993, and this amount has increased since then (Baumrucker, 
2002) to approximately $\$ 33.9$ billion in 2007 (Nahin, Barnes, Stussman \& Bloom, 2009). Common CAM techniques that are administered or recommended by professionals include: homeopathy, herbal medicine, aromatherapy, dietary supplements, megavitamins, acupuncture, probiotics, hypnosis, biofeedback, yoga and manipulative treatments (Cuzzolin et al., 2003). Common non-pharmacological techniques to alleviate pain at home include cognitive behavioral techniques (imagery, relaxation and selfregulation), massage, hot or cold compresses (AAP \& APS, 2001; Howard, 2003). Strategies, such as those listed, which alleviate distress or worry for parents and children have been found to reduce children's reports of pain symptoms and pain behaviors (AAP \& APS, 2001).

In a study assessing children's use of CAM techniques, researchers noted that approximately $41 \%$ of the population used at least one CAM technique in the past year (Crawford, Cincotta, Lim \& Powell, 2006). Researchers have reported, however, that parents were more likely to use CAM techniques for their children who experienced chronic concerns; estimates of CAM use in children match this finding with use at levels as high as $70 \%$ in children with chronic illnesses (Lim, Cranswick, Skull \& South, 2005). More conservative estimations of CAM techniques used for children indicate prevalence rates between 12 and 21\% (Sawni, Ragothaman, Thomas \& Mahajan, 2007). The wide variation in the prevalence rates of CAM technique use is most likely due to differences in the definitions of CAM techniques, as well as what non-pharmacological techniques are included as CAM techniques in particular studies.

Not all non-pharmacological techniques are appropriate for children of all ages and researchers have found that certain techniques are more helpful at certain ages. For 
preverbal children, stroking, soothing and distraction can be helpful to alleviate pain. Other comfort techniques are best used with infants and include pacifier, swaddling, massage, touch and sucrose solution. Recommendations involving use of imagination, such as suggesting to children that they have a magic glove or blanket to reduce their pain, work well for children between the ages of 5 and 10 years. Adolescents benefit from various techniques including physical responses (crying or screaming), passive acceptance, cognitive processes (imagery or positive self-talk), avoidance (closing eyes) and active control (holding someone's hand). Breathing techniques and distraction work well with all children over the age of 2 years (Bauchner, Vinci \& May, 1994; Rusy \& Weisman, 2000).

\section{Enabling Factor: Decisions about Treatment Options}

There are multiple reasons why people turn to CAM techniques to help alleviate their pain. Individuals often turn to professionally provided CAM techniques because these techniques are thought to supply the individuals with more opportunities to be included in the treatment decisions (Bishop, Yardley \& Lewith, 2007). In studies assessing alternative techniques used by parents to help alleviate their children's pain, researchers have found that parents reported use of CAM techniques because the techniques were recommended by family or friends, parents reported concerns about side effects from conventional medications (Cuzzolin et al., 2003; Spigelblatt, Laîné-Ammara, Pless \& Guyver, 1994; Vlieger, Blink, Tromp \& Bennings, 2008), CAM provider's promise to cure child's illness, child's medical problem was long lasting (Fernandez, Stutzer, MacWilliam \& Fryer, 1998; Simpson \& Roman, 2001), and parents felt dissatisfaction with conventional medicine (Cuzzolin et al., 2003; Jean \& Cyr, 2006; 
Sawni et al., 2007; Spigelblatt et al., 1994; Vlieger et al., 2008). Aversion to conventional medications has been noted to be a lifestyle choice, such that some parents report always avoiding use of medications to alleviate their children's pain (Kankkunen et al., 2002). Parents have also reported using CAM techniques to increase their children's overall quality of health (Cuzzolin et al., 2003).

In studies assessing demographic characteristics of parents who report CAM technique use for their children, researchers have found that parents are more likely to use CAM techniques for their children if the parents had used CAM techniques themselves (Loman, 2003; Sawni et al., 2007). Researchers have noted that it is more likely for parents to use CAM techniques to treat their children if the mothers have higher levels of education (Spigelblatt et al., 1994) and have higher family incomes (Crawford et al., 2006). CAM techniques were also more likely used for children over the ages of 5 (Loman, 2003; Sawni et al., 2007; Spigelblatt et al., 1994).

In another study, however, it was noted that parents were more likely to use the techniques with children younger than 5 years of age. It is also unclear why this difference in technique use exists based on child's age. It may be due to parents' greater comfort using "natural" techniques with their younger children. Another possible reason for this difference based on child's age may be because CAM techniques have become more popular in recent years and parents of younger children tend to be younger themselves and more aware of techniques mentioned in popular media (Madsen et al., 2003).

Studies assessing parents' use of non-pharmacological techniques to alleviate their children's pain have thus far only included alleviation of post-operative pain both in 
the hospital and at home. One study divided the most frequently reported techniques by treatment taxonomy and found that the most common cognitive-behavioral techniques were distraction, imagery and preparatory information about the procedure. Many parents also used physical techniques such as positioning and massage, as well as emotional techniques including support and presence (He et al., 2006). In other studies, which focus on the uncategorized non-pharmacological techniques provided by parents for their children's post-operative pain, the general finding was that a wide variety of techniques were reported. One of the most commonly reported techniques across all the studies was distraction, which includes watching television, reading and relaxation (Idvall et al., 2005; Kankkunen, Vehviläinen-Julkunen, Pietilä \& Halonen, 2003a; Pölkki et al., 2002). Other non-pharmacological techniques reported by parents alleviating their children's post-operative pain, include touching the child, special feeding techniques, limiting child's playing, assisting the child in emotion regulation, administration of natural health store products, re-establishing joy, positioning, thermal compresses (Kankkunen et al., 2002), comfort, spending more time with child (Kankkunen et al., 2003a), presence in the room, and helping child with daily activities (Pölkki et al., 2002). In a review of nonpharmacological techniques used to alleviate procedural pain in infants and young children, it has been summarized that though there are many techniques available for use (e.g. swaddling, swallowing water, rocking/holding and distraction), the efficacy of these treatments for procedural pain is lacking (Pillai Riddell et al., 2011).

According to school-aged children's reports of non-pharmacological techniques provided by parents to alleviate post-operative pain in the hospital, the most commonly used techniques were distraction, presence in the room, praise and encouragement, and 
helping with daily activities (Pölkki, Pietilä \& Vehviläinen-Julkunen, 2003). Children reported that the most common techniques they used themselves to help alleviate postoperative pain were distraction, resting, sleeping, positioning and asking for pain medication or help from medical professionals (Pölkki et al., 2003).

When considering demographic differences, in countries including China and Finland, of non-pharmacological techniques used to help alleviate children's postoperative pain in the hospital, researchers have found that mothers reported more frequent use of non-pharmacological techniques than fathers (He, Pölkki, Pietilä \& Vehviläinen-Julkunen, 2006). Within the techniques reported, fathers were more likely to use imagery, praise and encouragement, and creating a comfortable environment to alleviate their children's pain. When comparing type of technique used by child gender, it has been found that parents were more likely to use non-pharmacological techniques with their daughters than their sons (Pölkki, Vehviläinen-Julkunen \& Pietilä, 2002). The nonpharmacological techniques used by parents also differed based on their child's gender with parents being more likely to hold the child, read with them or tell them to watch television if the child was a girl (Kankkunen, Vehviläinen-Julkunen, Pietilä \& Halonen, 2003b), and more likely to use massage with girls than boys, and praise and encouragement with boys than girls (He et al., 2006).

\section{Enabling Factor: Conversations with Healthcare Providers}

Despite parents' perceptions that non-pharmacological techniques (Crawford et al., 2006) and OTC medications are safe and free of side effects or risks (Birchley \& Conroy, 2002), these techniques are not always safe and may have side effects or contraindications with other techniques for pain relief (Crawford et al., 2006). It is 
important for parents to openly discuss the range of techniques they are using to care for their child's pain with their physicians. The research unfortunately indicates that very few parents actually talk to their physicians about the non-prescribed techniques they are using to alleviate their children's pain (Crawford et al., 2006; Fernandez et al., 1998; Sawni et al., 2007).

When parents use non-pharmacological techniques with children at home, it is important for physicians to assess the potential for adverse interaction with pharmacological techniques (Crawford et al., 2006). This is of particular importance because researchers have found that parents are more likely to use non-pharmacological techniques together with conventional medicine instead of as an alternative to conventional medicine (Sawni-Sikand, Schubiner \& Thomas, 2002), creating a higher probability of contraindications between the non-pharmacological and pharmacological treatments. For parents using non-pharmacological techniques instead of pharmacological techniques to treat their children's pain, it is important for physicians to clearly explain to them that appropriate levels of analgesics should always be used if necessary and that non-pharmacological techniques may not effectively treat their children's pain (Berde \& Sethna, 2002).

It may be difficult for physicians to initiate the conversation with parents about their use of non-pharmacological techniques, as physicians often feel like they do not know enough about the non-pharmacological techniques used by their patients to help them make decisions about their children's care (Ernst, 1999). As well, physicians may be hesitant to provide recommendations for non-pharmacological techniques due to the lack of research indicating the efficacy of the non-pharmacological techniques used 
(Tasso \& Behar-Horenstein, 2004). As a result, the responsibility for initiating the conversation may fall to the patient, which research indicates is not likely to result in effective communication regarding non-pharmacological techniques used.

In the child patient literature, studies assessing parents' use of CAM techniques for their children found that only about $40 \%$ of parents reported information to their children's medical provider about the techniques used to treat their children at home (Crawford et al., 2006; Fernandez et al., 1998; Sawni et al., 2007). Commonly reported reasons for lack of disclosure were that the parents did not think the medical provider had time to consider the non-prescribed treatments or did not have interest in hearing about the unconventional techniques they used (Crawford et al., 2006). Bishop and colleagues (2007) have observed that adults who use non-pharmacological techniques are more likely to believe that there is a psychological aspect to the physical concern than individuals who did not use non-pharmacological techniques. It may be therefore that parents are unlikely to discuss their children's use of non-pharmacological techniques because they view the non-pharmacological techniques as treating the psychological constructs and not the physical symptoms that are often reported to physicians. It is important for medical providers to explain to parents the importance of full disclosure of all treatments used to treat their children's pain regardless of the perceived mechanism of treatment addressed by the techniques used.

\section{Predisposing Factor: Developmental Changes Influencing Treatment Choice}

It is of interest to question the potentially developmental reasons older children may have different patterns of use of pain alleviation techniques. As children transition into adolescence, they often exhibit a desire for a reduction in the time spent with their 
parents (Crosnoe \& Trinitapoli, 2008; Fuligni \& Eccles, 1993) and an increase in the time spent alone or outside of their home environment (Larson, Richards, Moneta, Holmbeck \& Duckett, 1996). Specifically, this transition towards increased autonomy and less time with parents theoretically occurs when children are around 12 years of age, transitioning from elementary school towards high school via their experiences in middle school. Therefore, children around the age of 12 years can be considered adolescents as these children share their perceptions of social interactions and importance of peers more similarly with older adolescents than with younger school-age children (Wilson, St. George \& Zarrett, 2010). During adolescence, individuals tend to prefer to assert their autonomy and independence and these assertions can influence their decisions regarding disclosure of pain experiences to parents and requests for treatment assistance. Specifically, there is a general decrease in parental influence as youth transition into late adolescence (Hill, Bromell, Tyson \& Flint, 2007), and an increase of adolescents' desires to participate in making decisions for themselves (Fuligni \& Eccles, 1993; Pinzon, Jacobson \& Reiss, 2004). Adolescents have been noted to oppose most strongly to their parents' attempts to influence decisions related to personal issues such as control over their bodies and privacy (Smetana, Metzger, Gettman \& Campione-Barr, 2006; WrayLake, Crouter \& McHale, 2010). Researchers have also indicated that it is during adolescence that children strive for more autonomy regarding their own healthcare, specifically diabetes (Palmer et al., 2009). These personal issues relate strongly to decisions regarding treatments of pain experiences, specifically pain experienced and treated at home. 
Providing adolescents with the opportunity to share their opinions and be active participants in decisions about themselves has been found to increase positive and healthy behaviors (Pinzon et al., 2004). As children progress into adolescence, they should be given increased opportunities to make decisions regarding their medical care (Committee on Bioethics, 1995). It has been noted that when making health care decisions, older adolescents are often able to make decisions in a similar fashion to adults; however adults tend to make better decisions because of their past experience with health care (Piker, 2011) and information they use to make decisions (Cauffman \& Steinberg, 2000). Adults tend to react more quickly to health threats and take into consideration future health outcomes (Wamboldt, Bender \& Rankin, 2011).

The overall reduction in time spent with parents and desire to increase autonomy, specifically for personal issues, could lead to changes in decision-making regarding treatment of pain experiences. For example, adolescents may be more inclined to use non-pharmacological techniques on their own than to request assistance from their parents, such as analgesics to alleviate their pain. As adolescents transition from relying on their parents to make decisions for them to self-reliance in decision-making, there is room for adolescents to choose which pain experiences they would like to treat on their own and which experiences they are more likely to continue eliciting assistance from their parents (Lorenc et al., 2009).

\section{Needs Factor: Parents' Level of Pain Catastrophizing}

Parents' use of pain reduction techniques for their children can also be influenced by their perceptions of control over their child's pain experiences (Caes, Vervoort, Eccleston, Vandenhende \& Goubert, 2011). Researchers have noted that psychological 
factors are important in the level of individuals' understanding of their pain experiences (Sullivan et al., 2001). For example, mothers who report more personal illness also recognize more illness experiences in their children (Melamed \& Bush, 1985), which can alter their report of frequency of pain treatments. Sullivan and colleagues (2001) describe pain catastrophizing, the most important psychological factor influencing the pain experience, as "a tendency to magnify or exaggerate the threat value or seriousness of the pain sensations" (p. 53). Individuals who perceive themselves to have less control over their pain often display pain catastrophizing behaviors and cognitions. Pain catastrophizing cognitions are based on the threat of pain and the concept that individuals believe their experiences of pain will be uncontrollable and associated with high levels of fear of pain (Vervoort, Goubert, Eccleston, Bijttebier \& Crombez, 2006).

Higher pain catastrophizing has shown high correlations with high reports of pain (Bennett-Branson \& Craig, 1993), and more intense emotions related to the experience of pain (Sullivan et al., 2001). Researchers have hypothesized that this increase in reports of pain and emotionality in reference to pain may be a result of individuals with high pain catastrophizing engaging people with low pain catstrophizing tendencies to attend to pain experiences; such that ignoring pain behaviors of high pain catastrophizers lead to an increase in pain behaviors (Gauthier, Thibault \& Sullivan, 2011). Researchers have noted in the chronic pain literature that parents who have higher levels of pain catastrophizing have a higher likelihood to reduce their children's pain-inducing activities and show efforts in protecting their children from new painful experiences (Caes et al., 2011; Langer, Romano, Levy, Walker \& Whitehead, 2009). Individuals who experience higher levels of pain catastrophizing often engage in higher levels of pain behaviors including 
verbal responses to pain (Sullivan et al., 2001). In response to these expressions of pain, parents' responses to their children's expressions of pain experiences can elicit differing levels of pain expressions in the future (Sullivan et al., 2001).

Varying levels of pain expressions could result in different choices of pain alleviation treatments. As noted above, non-pharmacological techniques can provide individuals with a reduction in distress and an overall sense of relaxation (Helmrich et al., 2001), which can lead to a reduction in pain intensity. Some parents however, may not be able to effectively provide their children with non-pharmacological techniques, such as relaxation and imagery, for their pain (Craig et al., 1996). It has been noted, by expert opinion, that many parents do not intuitively know how to assist their children in coping with painful medical procedures in the emergency department (Bauchner et al., 1994). Parents may require assistance in learning the most effective non-pharmacological techniques to help alleviate their children's pain. In a study assessing nurses' reports of helping parents with non-pharmacological techniques to alleviate the children's pain, it was noted that the techniques most commonly described to parents were distraction, positive reinforcement, comforting/reassuring, positioning and relaxation (He et al., 2006). These techniques could help reduce children's perceptions of their parents' levels of pain catastrophizing.

Parents and children who experience higher levels of pain catastrophizing may be inclined to use a wider variety of both pharmacological and non-pharmacological techniques to assist in reduction of their anxiety and distress regarding the pain experience. Regardless of levels of pain catastrophizing, all parents may use a combination of pharmacological and non-pharmacological techniques. 


\section{Needs Factor: Children's Expression of Pain}

Children learn from their parents how to cope with and respond to pain (Moon, Chambers \& McGrath, 2011), and often use similar techniques to their parents to alleviate pain (Evans, Tsao \& Zeltzer, 2008; Hermann, Zohsel, Hohmeister \& Flor, 2008). It is therefore important to understand how children express their pain to their parents and how parents interpret these expressions, as appropriate techniques must be taught for effective pain management. As with most people, children most often express pain via facial expressions and cues (Craig, 1998). However, researchers found that in a laboratory setting children were effective at suppressing their facial expressions related to temperature-induced pain experiences (Moon et al., 2011). As children age, they are more likely to suppress their pain expressions (Walker \& Zeman, 1992). Children also reported hiding their pain from their parents more frequently than faking pain (Moon et al., 2011). Both of these factors may result in parents' under-estimation of their children's pain experiences or intensity of pain. Researchers have noted that an individual's development of the concepts of pain does not rely on age. Therefore, all children, including infants, feel pain and in similar ways to adults both physiologically and psychologically. However, the ability to communicate these pain experiences develops throughout childhood. Notably, children experience pain and may not be able to effectively communicate these pain experiences to others, but this is not a valid reason to deprive children of treatment to alleviate their pain experiences (Gillies, 1993).

It has been noted in the pediatric pain literature that there is a wide range of child and parent concordance in estimations of pain frequency, duration and intensity, with most results indicate poor concordance between reporters (Chambers et al., 1998; Moon 
et al., 2008). Researchers have concluded that parents should not be the sole reporters on their children's pain experiences, as children can have their own subjective and most often different reports than their parents regarding their pain experiences (KrönerHerwig, Morris, Heinrich, Gassmann \& Vath, 2009). However, if children are not expressing their pain experiences or parents are not accurately interpreting their children's pain expressions, there is potential for oligoanalgesia to occur.

\section{Limitations of Current Literature and Future Directions}

As is evident from the literature reviewed above, much of the research regarding use of non-pharmacological techniques with children has been based on post-operative pain or professionally provided CAM techniques (He et al., 2006; Idvall et al., 2005; Kankkunen et al., 2002; Kankkunen et al., 2003b). This information is beneficial in guiding parents and health care professionals in their understanding of which techniques can be useful to alleviate children's pain; however most pain in childhood is not postoperative and is treated at home (Finley et al., 1996; Forward et al., 1996; Neill, 2000). It is therefore important to understand techniques parents are using at home to treat their children's everyday pain. The CAM techniques provided by professionals are inherently different than the techniques provided by parents (Bassols, Bosch \& Baños, 2002) as most parents are not trained to provide these techniques, such as homeopathy and acupuncture. As well, the techniques used for post-operative pain may be different from the techniques used for everyday pain, since post-operative is likely to be more severe than everyday pain experienced by children. While the previous literature is informative regarding techniques used for children's pain, it is insufficient for a comprehensive understanding of how parents treat their children's pain at home. 
As can be seen above, parents often express concerns about pharmacological techniques, such as side effects and addiction, which are not accurate for their children (Friedrichsdorf \& Kang, 2007; Idvall et al., 2005; Kankkunen et al., 2002). As well, it has been noted that individuals use non-pharmacological techniques because of their discontent with the medical system and their desire for a stronger internal locus of control regarding their care (He et al., 2006; Pederson \& Harbaugh, 1995). It is of relevance to ascertain more information about parents' behaviors in treating their children's pain at home with non-pharmacological techniques. It is of specific interest if parents' decisions are influenced by their desires to avoid pharmacological techniques due to the reasons stated above, such as concerns about addiction and side effects.

It is clear that children's pain is not effectively treated in many cases. Increased communication between parents and appropriately-trained medical providers and addressing parents' false beliefs about childhood pain and pain treatments will both likely lead to an increase in the effectiveness of treatment of children's pain. As the literature indicates, there is currently limited dialogue between patients and medical providers regarding the use of non-prescribed treatments (Crawford et al., 2006; Fernandez et al., 1998; Sawni et al., 2007). Not only is it important to increase communication between parents and medical providers so that children can be provided with more effective and comprehensive treatment, it will be useful to learn what influences parents' decisions to talk to their children's medical providers about non-pharmacological and non-prescribed pharmacological techniques used at home to alleviate their children's pain. The research to date regarding the use of pharmacological and non-pharmacological techniques has largely been based on populations outside of the United States. Though these studies help 
provide a basis of understanding regarding potential patterns of parents' use, it is important to note that this is the first study focused on parents' use of pain alleviation techniques at home in the United States. 


\section{Current Study}

The current study adds to the literature by examining the use, and reasons of use, of non-pharmacological and pharmacological techniques for the treatment of pain in a sample of community youth. The participants in the current study were community parents rather than those from a pediatric medical setting, thereby providing a unique perspective of techniques used by parents at home. The community sample results will be more generalizable to the broader non-clinical sample of parents treating their children's pain experiences at home. Assessment of the use and reasons of use of pain alleviation techniques by parents for their children's pain at home provides further information for health care professionals to promote discussions with parents regarding pain alleviation technique options. The current study increases the understanding of parents' use of pharmacological and non-pharmacological techniques to treat their children's pain at home. Based on the current literature and Andersen's model of health care utilization the following hypotheses were addressed.

Initially, an assessment of parents' use of both pharmacological and nonpharmacological treatment options was conducted. The hypotheses in this context are that: most parents report using pharmacological techniques and most parents report somewhat or high levels of comfort providing their children with medication to reduce their pain. As well, it is hypothesized that most parents will report using nonpharmacological techniques to reduce their children's pain. In previous research, it was noted that $98 \%$ of the parents in a similar community sample reported using at least one non-pharmacological technique to help alleviate their child's pain (Gorodzinsky, Bernacki, Davies, Drendel \& Weisman, 2012). 


\section{Hypotheses}

In Andersen's model, the three main factors leading to health care utilization decisions are predisposing, enabling, and needs factors. Hypotheses based on the needs factors of the model are the following:

I: Parents who report worry regarding providing medications to their children will be more likely to report using a wider variety of non-pharmacological techniques to treat their children's pain. This hypothesis is based on parents' assessments of whether their children's need for care is high enough to warrant use of medications that are thought to result in undesirable side effects. Past literature has indicated that parents are likely to worry about side effects of medications including addiction and overuse which can lead to inadvertent under-medication of pain (Finley et al., 1996; Forward et al., 1996).

II: Parents who report higher levels of pain catastrophizing will be more likely to report use of a wider variety of both pharmacological and non-pharmacological techniques. Pain catastrophizing can directly influence parents' perceptions of need for treatment for their children's pain as it has been noted in the literature that individuals with high pain catastrophizing are more likely to infer higher levels of pain in other people (Sullivan, Martel, Tripp, Savard \& Crombez, 2006), and therefore more likely to engage in pain behaviors including treatment of pain experiences. Individuals with high pain catastrophizing may be more likely to detect pain behaviors and respond quickly with treatment than individuals with low pain catastrophizing (Sullivan et al., 2006).

Hypotheses based on the predisposing factors, including demographic factors, of the model as follows: 
III: Parents will be more likely to report using a wider variety of nonpharmacological techniques with their younger children as compared to their adolescent children. In the literature there is discrepancy regarding patterns of use of nonpharmacological techniques based on children's age, with some researchers noting that parents are more likely to use non-pharmacological techniques with children younger than 5 years and other researchers noting more use with children older than 5 years (Loman, 2003; Madsen et al., 2003; Sawni et al., 2007; Spigelblatt et al., 1994). It is hypothesized in the current study that parents' concerns regarding providing their children with pharmacological medications due to perceived adverse effects will lead parents to use a wider variety of non-pharmacological techniques instead of medications to alleviate their children's pain. Participants' reports were divided into two groups: those of children 11 years of age and younger and those of adolescents 12 years of age and older. These two groups were created based on developmental influences in childhood, specifically increases in autonomy, independence (Crosnoe \& Trinitapoli, 2008; Fuligni \& Eccles, 1993), and understanding the relationships between personal and environmental influences on decisions (Wilson et al., 2010).

IV: Parents' reports of child self-administration of pain alleviation techniques will increase based on child's age. This hypothesis is based on the knowledge that as children progress into adolescence there is an increase in their desire for autonomy regarding decisions of their body (Smetana et al., 2006; Wray-Lake et al., 2010).

Exploratory analyses based on the predisposing factors of demographics were also conducted. Specifically, these analyses assess the patterns of technique use based on 
gender and age of the parents and children. Therefore, no specific hypotheses were created with regards to these factors.

The hypothesis based on the enabling factors of the model is formed on the concept that discussions with medical providers are directly related to parents' ability to access healthcare and perceived ability to influence the healthcare they can access (i.e. believing that having discussions with their medical provider will alter the care their children receive):

V: Parents will be more likely to report having spoken to a medical provider about pharmacological techniques than non-pharmacological techniques for treating pain at home. This hypothesis is based on the literature that parents perceive many potential adverse effects related to medications (AAP \& APS, 2001; Finley et al., 1996; Mathews, 2011) and tend to view non-pharmacological techniques as safe and natural (Birchley \& Conroy, 2002; Crawford et al., 2006). This perception of non-pharmacological techniques can lead parents to assume that these techniques have limited or no potential adverse effects. 


\section{Method}

This study was a part of a larger study assessing parents' perceptions of various aspects of their children's health and health-related quality of life. The questions relevant to this current study were one section of a longer survey completed by participants. The study had appropriate Institutional Review Board approval.

\section{Participants}

The study had several collections of participation within three semesters (spring, summer and fall 2011); these collections were, respectively, 1) parents of children aged 6 to 12 years, 2) parents of adolescents aged 12 to 17 years, and 3) parents of adolescents aged 12 to 17 years. Parents were eligible for inclusion in the current study if they had children in their home between the ages of 6 to 17 years and were English speaking.

\section{Procedure}

Recruitment for all semesters began with undergraduate students recruiting parent participants as part of their course requirements for a psychology laboratory course. Students recruited potential participants and explained that the online survey was anonymous and provided the participants with an information sheet that outlined the survey and the importance of informed consent. Upon expressing verbal consent, participants were given instructions regarding how to access the online survey at SurveyMonkey.com. This online survey service collected participants' data anonymously. Each participant entered a unique identification numbers connected only to the student who recruited him or her for the study; and this number did not include any personal information. The first page of the survey included confirmation that participants were over 18 years of age and the participant was voluntarily completing the survey. For 
participants without internet access or those who did not want to participant online, students provided the option to complete the survey on paper.

In previous samples using this collection technique, the majority of the participants were Caucasian and highly educated. Though this reduces the generalizability of the results, it provides more information regarding use of nonpharmacological and pharmacological techniques used to treat pain at home than has been previously available in the literature.

\section{Measures}

The study was conducted using an anonymous online survey, during which parents were asked to answer all questions while keeping in mind a particular child in their family within the specified age group. The current study focused on questions related to participants' opinions, comfort with, use, and reasons for use of pharmacological and non-pharmacological techniques for treating their child's pain (adapted from Drendel et al., 2006). Participants answered questions regarding frequency and location of pain experiences, comfort and concerns regarding use of pharmacological techniques to treat pain, patterns of use of pharmacological and non-pharmacological techniques to treat pain, and conversations with others (including health professionals) regarding use of these techniques to treat pain (survey questions relevant to current study can be seen in the Appendix).

Parents also filled out the parent-report version of the Pain Catastrophizing Scale (PCS-P; Sullivan, Bishop \& Pivik, 1995).The PCS-P measures a parent's tendency to catastrophize about their child's pain experiences. The measure has three subscales (hopelessness, magnification, and rumination) and a total score. Total scores on the 
measure range from 0 to 52 , with scores above 20 being in the at-risk range and those above 30 in the clinical range. This measure has been assessed for validity and factor structure. Initial assessment of the psychometrics of this measure noted that the measure had acceptable Cronbach coefficient alphas for all subscales and total scale score (Rumination, Magnification, Helplessness and Total; 0.87, 0.60, 0.79 and 0.87, respectively; Sullivan et al., 1995). Further assessment of the measure by confirmatory factor analysis was consistent with the pre-established measure factors. The psychometric analysis of the measure also indicated concurrent validity with measures of anxiety, and predictive validity of individuals seeking clinical treatment versus non-clinical samples (Osman, Barrios, Kopper, Hauptmann, Jones \& O’Neill, 1997). It has been found that the PCS-P has acceptable construct and criterion validity as tested with parents of clinical and community children. Specifically, the measure had Cronbach coefficient alphas ranging from 0.78 to 0.93 for the three subscales and the total score $(0.78,0.84,0.89$ and 0.93 for chronic pain sample and $0.81,0.91,0.82$ and 0.93 for the community sample, for Magnification, Rumination, Helplessness and Total, respectively; Goubert, Eccleston, Vervoort, Jordan \& Crombez, 2006). The Total score was the only scale used from this measure in the current study, and Cronbach's $\alpha$ of the measure in the current study was 0.93 .

\section{Data Analyses}

All statistical analyses were completed using SPSS version 17.0 (SPSS, Inc., 2008). Demographic data were analyzed using descriptive statistics. Hypothesis one was evaluated using independent sample t-tests between parents who report worry and parents who report no worry regarding providing medications to their children. Hypothesis two 
was evaluated using correlations of techniques used between parents with high levels of pain catastrophizing and low levels of pain catastrophizing. Hypothesis three was evaluated using an independent sample t-test to assess age differences in patterns of use of numbers of non-pharmacological techniques. Hypothesis four was assessed using visual inspection and ANOVA of number of pharmacological and non-pharmacological pain alleviation techniques self-administered by children by age. Hypothesis five was evaluated using a phi test between parents who discussed pharmacological techniques with medical provider and those who discussed non-pharmacological techniques with medical provider. 


\section{Results}

A total of 762 parents completed the questions in the survey for this study. Of the 762 parents, $517(67.9 \%)$ were mothers. The majority (73.8\%) of the sample was married. Among the other participants, $12.8 \%$ was divorced, $10.6 \%$ was single, $1.5 \%$ was separated and $0.5 \%$ was widowed. The sample was highly educated with 746 (97.9\%) reporting completing at least a high school education and $552(72.4 \%)$ completing at least an associate's degree. The majority of the sample (85\%) self-identified as Caucasian/White, followed by African-American/Black (5.9\%), Latino/a (2.9\%), Asian (2.1\%), Mixed (1.9\%), other (1.7\%) and Native American (0.4\%). Parents' age ranged from 18 to 65 years $(M=41.65, S D=7.79)$. The mean number of children for each parent was $2.46(S D=1.17)$.

The target children for the study ranged in age from 6 to 17 years $(M=12.72, S D$ $=3.41)$. The sample of children was split evenly between males and females $(50.3 \%)$. Nearly half of all parents noted that their children experienced pain less than once a month (see Table 1), and the most common pain locations were stomach, head and muscles (see Table 2). As this study assesses parents' use of techniques to alleviate their children's pain experiences at home, the following results include only those parents $(\mathrm{n}=$ 284) who reported that their children experienced pain at least once a month. There were no significant differences between this subset of parents and the subset of parents who reported that their children experience pain less than once a month on any of the following: demographic characteristics of parents and children, comfort with providing medications, worry about giving medications, total PCS-P scores, and breadth of pharmacological and non-pharmacological techniques provided. 
The majority of parents (92.9\%) reported feeling somewhat or very comfortable giving their children pain medication, while slightly less $(72.4 \%)$ reported no worry about giving pain medications. The potential negative consequences from medications reported as concerns by parents were overuse $(45.4 \%)$, drowsiness $(17.3 \%)$, nausea $(15.8 \%)$, and addiction (12.0\%). The majority of parents (98.6\%) reported use of at least one pharmacological technique. The most common pharmacological techniques provided were Advil/Motrin/ibuprofen (82.0\%), followed by Tylenol/acetaminophen (76.8\%), Aspirin (19.0\%), and opiates/narcotics (4.2\%). As well, the majority (98.9\%) of parents reported providing their children with non-pharmacological techniques to alleviate pain, the most common techniques provided were sleep, ice, comfort, and rub/massage (see Table 3).

Hypotheses:

I: Parents who reported worry regarding providing medications to their children and those who did not report worry were not significantly different in the variety of nonpharmacological techniques used to treat their children's pain $(t(129.72)=1.70, p=$ 0.092). Parent who reported worrying about providing medications reported using an average of $6.21(S D=3.05)$ techniques to alleviate their children's pain, and parents who reported no worry used an average of $5.53(S D=2.81)$ techniques.

II: Many (64.5\%) parents reported scores of 20 or higher, in the at-risk or clinical range, on the PCS-P. The mean score on the PCS-P was $23.89(S D=8.17)$, with scores ranging from 13 to 47 . Parents reported an average of $5.73(S D=2.88)$ nonpharmacological techniques and an average of $1.82(S D=0.77)$ pharmacological techniques used in the past. Total score on the PCS-P was not significantly correlated 
with the total number of non-pharmacological techniques used by parents $(r=0.073, \mathrm{~N}=$ $242, p=0.258)$. However, it was significantly correlated with the total number of pharmacological techniques used $(\mathrm{r}=0.19, \mathrm{~N}=242, p<0.01)$.

III: The sample was divided by children's age into two groups: less than or equal to 11 years and greater than 11 years of age (see Table 4). There was no difference found in variety of non-pharmacological techniques used by parents of school-aged children ( $M$ $=5.97, S D=2.93)$ as compared to parents of adolescent children $(M=5.58, S D=2.87)$, $t(219.76)=1.09, p=0.279$.

IV: Parents' reports of child self-administration of pain alleviation techniques increased based on child's age. Regardless of age, $21.2 \%$ of parents reported that they would let their children take pharmacological techniques on their own, $27.9 \%$ reported that their child can take medications on their own if they check with a parent first, and $50.9 \%$ of parents reported that their child cannot take pharmacological techniques on their own to alleviate their pain. Most (76.5\%) of the parents reported they would let their child use non-pharmacological techniques on their own, $12.6 \%$ reported that the child must check with a parent first, and $10.8 \%$ of parents reported that their child could not use a non-pharmacological technique on their own.

The visual inspection of the self-administration graphs indicates that selfadministration does increase with children's age. Based on trends seen in these graphs, the sample was divided into three groups of children's ages: 6 to 11,12 to 15 , and 16 to 17 years (see Figures 3 and 4, and Table 4). An ANOVA test was conducted using these three age groups, and the results indicate a significant difference in self-administration 
based on child's age for both pharmacological and non-pharmacological techniques $(F(2,279)=178.99, p<0.01$ and $F(2,273)=4.31, p<0.01$, respectively $)$

$\mathrm{V}$ : Most (65.6\%) of the parents reported talking with their children's pediatricians about appropriate uses of pain medications, while slightly more than half $(51.6 \%)$ of the parents reported talking about non-pharmacological techniques to alleviate pain. A significantly greater proportion of the sample (26.9\%) reported discussing the use of pharmacological techniques but not non-pharmacological than the proportion of the sample $(7.0 \%)$ who discussed the use of non-pharmacological techniques but not pharmacological techniques, $\varphi(1, \mathrm{~N}=277)=0.59, p<0.01$. Parents also reported that they or another family member initiated the conversation more often than the provider (59.8\% versus $14.8 \%$ for pharmacological techniques and $57.5 \%$ versus $17.9 \%$ for nonpharmacological techniques, respectively).

Exploratory analyses were conducted regarding use of pharmacological and nonpharmacological techniques based on parent and child demographics, specifically age and gender. Parents' responses regarding their use of both pharmacological and nonpharmacological techniques were divided into two categories, presence or absence of use. The majority of parents (98.9\%) reported using at least one non-pharmacological technique and about the same number $(98.6 \%)$ reported use of at least one pharmacological technique.

No significant differences in use of either type of technique were found based on parents' age. Specifically, parents' age did not significantly differ between the parents who used pharmacological techniques $(M=40.99, S D=7.91)$ and those who did not $(M$ $=39.75, S D=8.62) ; t(3.07)=0.31, p=0.79$. Parent's age also did not significantly differ 
between the parents who used non-pharmacological techniques $(M=43.0, S D=10.95)$ and those who did not $(M=40.43, S D=8.56) ; t(14.45)=2.57, p=0.524$.

With regards to gender, there was a significant difference between mothers and fathers regarding their use of non-pharmacological techniques with a significantly greater number of mothers $(\mathrm{N}=199)$ reporting use of these techniques than fathers $(\mathrm{N}=84 ; \varphi=$ $0.16, p<0.01)$. No significant difference was found based on parent's gender regarding the presence or absence of use of pharmacological techniques (mothers $\mathrm{N}=196$, father $\mathrm{N}$ $=83 ; \varphi=-0.01, p=0.836)$.

Parents were asked to identify which of the non-pharmacological techniques they use most often with their child, and there was a significant difference based on child's gender in the choice of technique $(\varphi=0.32, p<0.01)$. Specifically, a significantly greater proportion ( $81.8 \%$ of those parents who reported use of this technique) reported common use of rub/massage with their daughters than their sons $(18.2 \%)$, and a significantly greater proportion reported telling their sons to "suck it up" (100\% of those parents who reported common use of this technique) as compared to their daughters $(0 \%)$. However, it was found that there was no significant difference based on child's age category (divided into child: 11 years old and younger compared to adolescent: 12 years of age and older) for type of non-pharmacological technique used $(\varphi=0.25, \mathrm{p}=0.15)$. 


\section{Discussion}

This study examined the patterns of both pharmacological and nonpharmacological pain alleviation techniques used at home to alleviate children's pain. The assessment of patterns of use were based on a modified version of Andersen's sociobehavioral model, in which the three main factors leading to health care utilization decisions are needs, predisposing, and enabling factors. The hypotheses for this study were based on the factors in this model. The needs factors in the model were assessed based on parents' perceptions of pharmacological techniques and of the pain experiences, specifically their level of worry and catastrophizing about their child's pain experiences. Predisposing factors include demographic factors, therefore use of pain alleviation techniques based on child's age, both treatment provided by parent and child selfadministration were assessed, along with exploratory analyses based on parents' age, gender and child's gender. Enabling factors are those, which describe access to healthcare and how this access changes healthcare use, therefore enabling factors were assessed via parents discussions of pain alleviation techniques with their child's healthcare provider.

\section{Needs Factors Influencing Parents' Decisions of Pain Alleviation Treatments}

The first needs factor assessed was the presence of parental worry regarding providing medications to their children to alleviate pain in relation to parental use of nonpharmacological techniques. It was hypothesized that parents who report worrying about pharmacological techniques would be more likely to turn to non-pharmacological techniques to alleviate their children's pain. This was not found to be the case with the current sample of parents, with both groups of parents reporting similar breadth in the variety of non-pharmacological techniques used to alleviate their children's pain. 
Another needs factor is the individual's assessment of whether health care techniques are necessary or not. In the context of pain, this can be understood as the person's perception of their ability to alleviate the pain experience. Pain catastrophizing occurs when an individual exaggerates the threat of the painful experience and experience little to no control over their pain experiences (Sullivan et al., 2001). In the current study, parents who reported higher levels of pain catastrophizing regarding their children's pain experiences were more likely to report using a wider variety of pharmacological techniques, but there was no difference based on level of pain catastrophizing found in the number of non-pharmacological techniques used. It has been noted that within the pediatric chronic pain population that parents' personal level of pain catastrophizing can influence their treatment of their children's pain experiences (Lynch-Jordan, KashikarZuck \& Goldschneider, 2010). This may also be the case for community parents, with parents who have higher pain catastrophizing being more aware of pain behaviors and responding more quickly (Sullivan et al., 2006) and more intensely to pain experiences. Specifically, these parents may be more likely to initially alleviate the pain with the more intense treatment rather than gradually increase the intensity of treatment choices.

\section{Predisposing Factors Influencing Parents' Decisions of Pain Alleviation Treatments}

Predisposing factors are those that relate to demographic information such as age and gender. The current sample was divided based on child's age into two groups, children and adolescents. It was found that parents report using similar breadths of variety of non-pharmacological techniques with their children and adolescents. Past literature has revealed discrepancies regarding patterns of non-pharmacological technique use based on children's age (Loman, 2003; Madsen et al., 2003; Sawni et al., 2007; 
Spigelblatt et al., 1994). However, this literature was based on samples divided at the age of 5 years, while the current study divided children at the age of 12 years and did not include children under the age of 6 years. This indicates that there may be some differences in parents' patterns of using non-pharmacological techniques, and that these differences may be more likely to exist between the preschool and school-age children than between school-age and adolescent children. Further research is necessary to explore a wider range of children's age to include those under 6 years of age to adolescence.

Self-administration of pain alleviation techniques was also influenced by developmental factors, specifically child's age. As children proceed into adolescence, there is an increase in the desire to assert autonomy and make decisions regarding health and the body (Smetana et al., 2006; Wray-Lake et al., 2010). Self-administration of pain alleviation techniques did increase as children transitioned into adolescence. This trend will most likely be helpful for healthcare providers to assist in making decisions regarding whether treatment options and instructions should be given to parents or children/adolescents during healthcare visits. Though this information is pain specific, it is likely that this trend of increased autonomy exists for other physical and medical decisions as well.

Most parents reported using both pharmacological and non-pharmacological techniques; therefore, it was of interest to explore if there were any gender or age differences regarding the use of techniques. In the current sample, there was no difference found based on parental gender regarding use of pharmacological techniques, but there was a significant difference found in use of non-pharmacological techniques with mothers being significantly more likely to use non-pharmacological techniques than 
fathers, which is consistent with previous literature (He et al., 2006). In the selection of non-pharmacological technique most often used, there was a significant difference based on child's gender regarding choice of technique with parents more likely to use $\mathrm{rub} / \mathrm{massage}$ with their daughters than sons and more likely to tell their sons than daughters to "suck it up" when the child is in pain. This is consistent with past literature, specifically in the post-operative use of non-pharmacological techniques, in which researchers found that parents were more likely to hold their daughters (Pölkki et al., 2002), and provide massage (Kankkunen et al., 2003b); while parents were more likely to use encouragement with sons (He et al., 2006).

With regard to age, there were no differences found for use of either type of technique. Specifically, there were no differences for use of either pharmacological or non-pharmacological techniques based on parents' age or children's age. The exploratory nature of this assessment provides information regarding parents' use of techniques based on their own characteristics. The finding based on children's age is somewhat contradictory to past literature, which notes that certain types of non-pharmacological techniques are more often used with certain age groups. However, the results from the past literature were specific to post-operative populations, and therefore may not be comparable to the current community sample.

\section{Enabling Factors Influencing Parents' Decisions of Pain Alleviation Treatments}

As explained in Andersen's model, treatment choice decisions are influenced by various factors. It may be thought that decisions regarding treatment choices at home do not require information available from healthcare providers. However, it has been noted in past literature that techniques deemed by parents are "safe" or "natural" can actually 
result in undesirable side effects or involve some level of contraindication with other pain alleviation techniques (Birchley \& Conroy, 2002; Crawford et al., 2006). Unfortunately, this seems to have been the common perspective of many parents in the current study sample; parents were more likely to report having spoken to their child's pediatrician about pharmacological techniques than non-pharmacological techniques for treating pain at home.

However, the potentially greater concern is that most parents reported that they or another family member initiated the conversation regarding treatment options. It is important for healthcare providers to be aware of their patients' treatment choices in order to provide viable and sustainable treatment options that are consistent with the treatment choices already in use. It has been noted in the literature that medication adherence increases when patients are educated about the treatment plan and have motivation to complete the treatment plan (Roter \& Hall, 1994). Therefore, healthcare providers must be in tune with their patients' current treatment decisions to provide appropriate and consistent treatment choices for future use. As well, the patienthealthcare provider relationship is strengthened when the patient and provider work together to create a treatment plan (DiMatteo, 1994). If the provider initiates the conversation and discusses both pharmacological and non-pharmacological techniques to alleviate childhood pain at home, parents may have increased motivation to engage in appropriate use of both types of techniques, thereby reducing the chances of oligoanalgesia for their children in the future. 


\section{Study Limitations}

The current study has several limitations. The most pronounced are those related to the study sample, specifically the limited ethnic diversity, high education level and imbalance in the sample between school-aged children and adolescents. The sample was predominantly Caucasian (85\%) and living in Wisconsin $(86 \%)$, indicating that the results may not generalize to other racial/ethnic groups and individuals living in other parts of the country or other countries. Future research should assess if the results found in the current study generalize to other populations, specifically more diverse populations and those living in other areas of the country. As well, in the current sample the parents were highly educated, which may lead to variant patterns of use compared to parents with lower levels of education and to differential comfort initiating conversations with healthcare providers. No direct measure of socioeconomic status (SES) was employed in the current study, which should be considered as a variable for future research.

The current study sample was assembled from three collections of participants each of which included parents of children from a particular age group. Despite intentions to recruit parents of three different children's age groups for each semester, two groups of parents of adolescents were recruited while one collection was of parents of children aged 6 to 12 years. This structure of data collection led to an imbalance in the sample sizes, with approximately twice as many adolescents as school-age children, when the children were divided into various age categories based on hypotheses. However, even when the sample was divided based on child's age, the category sample sizes were still large which led to the assumption that the results were valid. 
Other study limitations exist due to the nature of the data collection via online survey. Parents in this study were a convenience sample, and therefore there may be a selective bias regarding who was willing to complete an online survey. However, the demographics and patterns of use found in this study are similar to results from other parent samples (Gorodzinsky et al., 2012) indicating that the current sample captured an acceptable sample of parents. The survey was completed retrospectively; therefore there may be inaccuracies in parents' reports of patterns of use and discussions with healthcare providers.

The survey questions included in this study were part of a larger survey, which included questions regarding various aspects of children's health. The questions for the current study were near the beginning of the survey for two semesters, and near the middle of the survey in the third semester. It was assumed that this variation in location of study questions within the surveys would not influence parents' completion of the survey. As well, participants who displayed inconsistent responding to study questions and those who consented to the survey and did not respond to any of the questions relevant to the current study $(n=79)$ were removed from the data set prior to analyses.

\section{Future Research}

A major factor in Andersen's sociobehavioral model leading to decision of treatment is the outcome of past treatments used. This factor should be included in future research to assess the influence of perceived helpfulness and effectiveness of particular treatment options on future use of those options. Additionally, the current study was asking parents to report on use of techniques retrospectively, and therefore it is unclear if these techniques were being used whenever their children were experiencing pain or if 
the parents used the techniques merely at some point in the past. Future research assessing use of techniques at the time of the pain experience would further the understanding of parents' decision-making process and the factors influencing the decision.

A factor that likely differentiates between the use of pharmacological and nonpharmacological treatment choices is pain catastrophizing. Future research should assess if parents who have higher levels of pain catastrophizing are more likely to initially use pharmacological techniques prior to using non-pharmacological techniques. Parents with higher levels of pain catastrophizing may be more likely to initially attempt to alleviate their children's pain with the more intense treatment rather than gradually increase the intensity of treatment choices, specifically beginning with pharmacological choices and then supplementing with non-pharmacological techniques. It would be of interest to assess if parents' level of pain catastrophizing and order of pain alleviation technique choice influence children's long-term patterns of pain expression and pain catastrophizing. This would supplement the literature thus far, which states that parental catastrophizing tends to explain child's pain intensity and that parental pain catastrophizing is related to increased provision of concerned responses to pain expression (Hechler et al., 2011). Researchers have also noted that parents with higher levels of pain catastrophizing are likely to restrict their children's engagement in painful activities (Caes et al., 2011), therefore it would be of interest to assess differences in nonpharmacological techniques of choice for parents with higher levels of pain catastrophizing as compared to those chosen by parents with lower levels. 
The current study adds to the literature regarding developmental influences on parents' use of non-pharmacological techniques, with parents using similar breadth of variety of non-pharmacological techniques with their children under the age of 12 years as compared to those between 12 and 17 years. Previous literature provides only contradictory findings regarding developmental influences on the use of nonpharmacological techniques, and in this past literature samples were divided at the age of 5 years not 12 years. Future research is necessary to explore the developmental influences on parents' patterns of using non-pharmacological techniques (and pharmacological techniques) on a wider range of children's ages. 


\section{Conclusions and Implications}

The results from this study indicate that there are multiple factors influencing decisions regarding use of pain alleviation techniques at home. Key empirical findings of this study were:

1) most parents provided both pharmacological (98.6\%) and non-pharmacological $(98.9 \%)$ techniques,

2) $7.1 \%$ of parents were very uncomfortable giving pain medications,

3) $27.6 \%$ of parents reported at least some worry about giving pain medications, 4) the most common (45.4\%) concern about giving medications was "overuse",

5) parents who were worried about pain medications reported using the same breadth of variety of non-pharmacological techniques as parents who did not report worry, 6) parents with at-risk or clinical levels of PCS-P scores regarding their children's pain were more likely to use a wider variety of pharmacological techniques than parents with average levels of PCS-P scores,

7) parents of school-aged children reported a similar breadth of variety of nonpharmacological techniques as compared to parents of adolescents,

8) self-administration of both pharmacological and non-pharmacological techniques increases with child's age with many parents allowing self-administration of pharmacological techniques by age 16 , and self-management of non-pharmacological techniques allowed as early as age 6 , and 9) parents were more likely to talk to their child's physician about pharmacological techniques than non-pharmacological techniques. 
The current study provides information regarding the general experience of childhood pain, which adds to past literature regarding treatment of childhood pain at home focusing on the experience of chronic pain or post-operative pain. The parents in the current study were recruited from the community with the intention that their responses may provide information that can be generalized to other community parent populations. The current study was retrospective, however, and therefore it is unclear if the variables assessed influenced the treatment choices or if the treatment choices influenced the parents' responses. Regardless of the path of influence regarding the treatment choices, the current study provides information that has been previously overlooked in the pediatric pain literature. Data from the current study elucidates the importance of healthcare providers understanding the factors leading to parents' decisions regarding treatment of their children's everyday pain experiences at home. Healthcare professionals can use this information to provide appropriate and acceptable recommendations and education regarding the pain experience to parents in an effort to reduce pediatric experience of oligoanalgesia.

Within the structure of Andersen's sociobehavioral model of healthcare utilization, the current study focused on parent and child variables within the three factors (needs, predisposing and enabling), specifically parents' worry about providing medication, parents' level of pain catastrophizing, parents' age and gender, child's age and gender, child's self-administration of treatment techniques, and discussions with child's pediatrician about treatment options. While many other variables within the three factors of the model can be assessed in the future, the current study provides the initial analyses of variables influencing parents' decision-making process of treating their 
children's everyday pain at home, and indicates that future research regarding treatment of children's everyday pain experiences at home would be beneficial and informative.

Assessment of the results from the current study and past literature indicate that there are several factors influencing parents' decisions regarding use of treatment to alleviate their children's pain at home. This information was utilized to create a proposed model towards decisions regarding treatment and influence of treatment outcomes (see Figure 5). Unfortunately, children continue to experience oligoanalgesia (AAP \& APS, 2001; Mathews, 2011) and there is limited conversation between parents/children and medical providers regarding treatments of choice for children's pain experiences (Crawford et al., 2006; Fernandez et al., 1998; Sawni et al., 2007).

An increase in medical providers' education regarding effective treatment options for children with acute pain has been shown to increase effective pain management and reduce oligoanalgesia in the hospital (Price, Ong, Isedale \& Mackellar, 2011). Providing increased and continual education to medical providers could lead to increased parents effectively managing their children's pain via conversations initiated by medical providers to educate and collaborate with parents regarding treatment options (see Figure 6). As well, if medical providers are properly trained regarding treatment options at home, the conversations with parents regarding alleviation of childhood pain can lead to reductions in parents' level of worry regarding analgesics and levels of pain catastrophizing.

Childhood pain is a common experience; however an increase in understanding of these pain experiences and continued education for medical providers and parents can lead to increased effective treatment of these pain experiences and a reduction in 
oligoanalgesia. Future research should continue to assess factors influencing parents' decisions regarding treatment options, including but not limited to those outlined in Andersen's sociobehavioral model of predisposing, enabling and needs factors. Assessing these factors could assist medical professionals to provide appropriate and acceptable recommendations to parents and promote increased communication between parents, children and medical providers. As these factors become more integrated into these conversations and treatment decisions, both research and clinical knowledge could lead to effective treatment and reduced oligoanalgesia in childhood pain experiences at home unrelated to post-operative pain or chronic pain. 


\section{References}

American Academy of Pediatrics and American Pain Society. (2001). The assessment and management of acute pain in infants, children, and adolescents. Pediatrics, 108(3), 793-797.

Andersen, R. (1968). A behavioral model of families' use of health services. Research Series No.25, Chicago: Center for Health Administration Studies, University of Chicago.

Andersen, R.M. (1995). Revisiting the behavioral model and access to medical care: Does it matter? Journal of Health and Social Behavior, 36(1), 1-10.

Andersen, R. \& Newman, J.F. (1973). Societal and individual determinants of medical Care utilization in the United States. The Milbank Memorial Fund Quarterly. Health and Society, 51(1), 95-124.

Bassols, A., Bosch, F., \& Baños, J. (2002). How does the general population treat their pain? A survey in Catalonia, Spain. Journal of Pain and Symptom Management, 23(4), 318-328.

Bauchner, H., Vinci, R., \& May, A. (1994). Teaching parents how to comfort their children during common medical procedures. Archives of Diseases in Childhood, 70, 548-550. doi: 10.1136/adc.70.6.548

Baumrucker, S. J. (2002). Complementary medicine and the scientific method: mainstreaming proven "alternative" therapies. American Journal of Hospice and Palliative Medicine, 19(6), 369-371. doi:10.1177/104990910201900602

Bennett-Branson, S.M. \& Craig, K.D. (1993). Postoperative pain in children: Development and family influences on spontaneous coping strategies. Canadian Journal of Behavioural Science, 25(3), $355-383$.

Berde, C.B., \& Sethna, N.F. (2002). Analgesics for the treatment of pain in children. The NewEngland Journal of Medicine, 347(14), 1094-1103.

Birchley, N., \& Conroy, S. (2002). Parental management of over-the-counter medicines. Paediatric Nursing, 14(9), 24-28.

Bishop, F. L., Yardley, L., \& Lewith, G.T. (2007). A systematic review of beliefs involved in the use of complementary and alternative medicine. Journal of Health Psychology, 12(6), 851-867. doi: 10.1177/1359105307082447

Blount, R. L., Piira, T., Cohen, L.L., \& Cheng, P.S. (2006). Pediatric Procedural Pain. Behavior Modification, 30(1), 24-49. DOI: 10.1177/0145445505282438

Caes, L., Vervoort, T., Eccleston, C., Vandenhende, M., \& Goubert, L., (2011). Parental catastrophizing about child's pain and its relationship with activity restriction: The mediating role of parental distress. Pain, 152, 212 - 222. doi: 10.1016/j.pain.2010.10.037

Cantrill, J.A., Johannesson, B., Nicolson, M., \& Noyce, P.R. (1996). Management of minor ailments in primary schoolchildren in rural and urban areas. Child: Care, Health and Development, 22(3), 167-174.

Cauffman, E. \& Steinberg, L. (2000). (Im)maturity of judgment in adolescence: Why adolescents may be less culpable than adults. Behavioral Sciences and the Law, $18,741-760$. 
Chambers, C.T., Reid, G.J., Craig, K.D., McGrath, P.J., Finley, G. \& Allen, M.D. (1998). Agreement between child and parent reports of pain. The Clinical Journal of Pain, 14(4), 336-342.

Committee on Bioethics (1995). Informed consent, parental permission, and assent in pediatric practice. Pediatrics, 95(2), 314 - 317.

Craig, K.D. (1998). The facial display of pain. In G.A. Finley \& P.J. McGrath (Eds.), Measurement of pain in infants and children (pp. 103-122). Seattle, WA: IASP Press.

Craig, K.D., Lilley, C.M., \& Gilbert, C.A. (1996). Barriers to optimal pain management in infants, children and adolescents. Social barriers to optimal pain management in infants and children. The Clinical Journal of Pain, 12(3), 232-242.

Crawford, N. W., Cincotta, D. R., Lim, A., \& Powell C.V.E. (2006). A cross sectional survey of complementary and alternative medicine use by children and adolescents attending the University Hospital of Wales. BMC Complementary and Alternative Medicine, 6(16), doi:10.1186/1472-6882-6-16

Crosnoe, R., \& Trinitapoli, J. (2008). Shared family activities and the transition from childhood into adolescence. Journal of Research on Adolescence, 18(1), 23-48.

Cuzzolin, L., Zaffani, S., Murgia, V., Gangemi, M., Meneghelli, G., Chiamenti, G., \& Benoni, G. (2003). Patterns and perceptions of complementary/ alternative medicine among paediatricians and patients' mothers; a review of the literature. European Journal of Pediatrics, 162, 820-827. doi:10.1007/s00431-003-1313-9

DiMatteo, M.R. (1994). Enhancing patient adherence to medical recommendations. JAMA,271(1), 79.

Drake, R., \& Hain, R. (2006). Chapter 21: Pain - Pharmacological management. In: A. Goldman, R. Hain, \& S. Liben (Eds.), Oxford Textbook of Palliative Care for Children (pp. 304-331). Oxford, England: Oxford University Press.

Drendel, A. L., Brousseau, D. C., \& Gorelick, M. C. (2006). Pain assessment for pediatric patients in the emergency department. Pediatrics, 117(5), 1511-1518. doi: 10.1542/peds.2005-2046.

Drendel, A. L., Lyon, R., Bergholte, J., \& Kim, M. K. (2006). Outpatient pediatric pain management practices for fractures. Pediatric Emergency Care, 22(2), 94-99.

Ducharme, J. (2000). Acute pain and pain control: State of the art. Annals of Emergency Medicine, 35(6), 592-603. doi: 10.1067/mem.2000.106990

Ernst, E. (1999). Prevalence of complementary/alternative medicine for children: A systematic review. European Journal of Pediatrics, 158, 7-11.

Evans, S., Tsao, J.C.I., \& Zelzter, L.K. (2008). Relationship of child perceptions of maternal pain to children's laboratory and nonlaboratory pain. Pain Research \& Management, 13(3), 211-218.

Fernandez, C.V., Stutzer, C.A., MacWilliam, L., \& Fryer, C. (1998). Alternative and complementary therapy use in pediatric oncology patients in British Columbia: Prevalence and reasons for use and nonuse. Journal of Clinical Oncology, 16(4), 1279-1286.

Finley, G. A., McGrath, P. J., Forward, S. P., McNeil, G., \& Fitzgerald, P. (1996). Parents'management of children's pain following 'minor' surgery. Pain, 64, 8387. 
Forward, S. P., Brown, T. L., \& McGrath, P. L. (1996). Mothers' attitudes and behavior toward medicating children's pain. Pain, 67, 469-474.

Fuligni, A.J., \& Eccles, J.S. (1993). Perceived parent-child relationships and early adolescents'orientation toward peers. Developmental Psychology, 29(4), 622-632.

Friedrichsdorf, S.J., \& Kang, T.I. (2007). The management of pain in children with life limiting illnesses. Pediatric Clinics of North America, 54, 645-672. doi: 10.1016/j.pcl.2007.07.007

Gauthier, N., Thibault, P., \& Sullivan, M.J.L. (2011). Catastrophizers with chronic pain display more pain behavior when in a relationship with a low catastrophizing spouse. Pain Research \& Management, 16(5), 293 - 299.

Gedaly-Duff, V., \& Ziebarth, D. (1994). Mothers' management of adenoid-tonsillectomy pain in 4- to 8-year-olds: a preliminary study. Pain, 57, 293-299.

Gillies, M.L. (1993). Post-operative pain in children: a review of the literature. Journal of Clinical Nursing, 2, 5-10.

Gorodzinsky, A.Y., Bernacki, J.M., Davies, W.H., Drendel, A.L., \& Weisman, S.J. (2012). Community parents' use of non-pharmacological techniques for pediatric pain management. Children's Health Care, 41(1):1-15, doi: 10.1080/02739615.2012.643286

Goubert, L., Eccleston, C., Vervoort, T., Jordan, A., \& Crombez, G. (2006). Parental catastrophizing about their child's pain. The parent version of the Pain Catastrophizing Scale (PCS-P): A preliminary validation. Pain, 123, 254-263.

He, H., Pölkki, T., Pietilä, A., \& Vehviläinen-Julkunen, K. (2006). Chinese parent's use of nonpharmacological methods in children's postoperative pain relief. Scandavian Journal of Caring Sciences, 20, 2-9.

Hechler, T., Vervoort, T., Hamann, M., Tietze, A.L., Vocks, S., Goubert, L.,...Zernikow, B. (2011). Parental catastrophizing about their child's chronic pain: are mothers and fathers different? European Journal of Pain, 15(5):515.e1-9.

Helmrich, S., Yates, P., Nash, R., Hobman, A., Poulton, V., \& Berggren, L. (2001). Factors influencing nurses' decisions to use non-pharmacological therapies to manage patients' pain. Australian Journal of Advanced Nursing, 19, 27-35.

Hermann, C., Zohsel, K., Hohmeister, J., \& Flor, H. (2008). Dimensions of pain-related parent behavior: Development and psychometric evaluation of a new measure for children and their parents. Pain(137), 689-699.

Hill, N.E., Bromell, L., Tyson, D.F., \& Flint, R. (2007). Developmental commentary: Ecological perspectives on parental influences during adolescence. Journal of Clinical Child and Adolescent Psychology, 36(3), 367-377.

Howard, R.F. (2003). Current status of pain management in children. Journal of the American Medical Association, 290(18), 2464-2469.

Idvall, E., Holm, C., \& Runeson, I. (2005). Pain experiences and non-pharmacological strategies for pain management after tonsillectomy: a qualitative interview study of children and parents. Journal of Child Health Care, 9(3), 196-207. doi: $10.1177 / 1367493505054417$

International Association for the Study of Pain, Subcommittee on Taxonomy (1979). Pain terms: A list with definitions and notes on usage. Pain, 6, 249-252.

Jean, D., \& Cyr, C. (2007). Use of complementary and alternative medicine in a general pediatric clinic. Pediatrics, 120, e138-e141. doi: 10.1542/peds.2006-3105 
Kankkunen, P.M., Vehviläinen-Julkunen, K.M., \& Pietilä, A.K. (2002). Children's postoperative pain at home: Family interview study. International Journal of Nursing Practice, 8, 32-41.

Kankkunen, P.M., Vehviläinen-Julkunen, K.M., Pietilä, A.K., \& Halonen, P.M. (2003a). Parents' perceptions of their 1-6-year-old children's pain. European Journal of Pain, 7(3), 203-211.

Kankkunen, P.M., Vehviläinen-Julkunen, K.M., Pietilä, A.K., \& Halonen, P.M. (2003b). Parents' use of nonpharmacological methods to alleviate children's postoperative pain at home. Journal of Advanced Nursing, 41(4), 367-375.

Kankkunen, P.M., Vehviläinen-Julkunen, K.M., Pietilä, A.K., Kokki, H., \& Halonen, P. (2003c). Parents' perceptions and use of analgesics at home after children's day surgery. Paediatric Anaesthesia, 13, 132-140.

Kelner, M. \& Wellman, B. (1997). Health care and consumer choice: Medical and alternative therapies. Social Science \& Medicine, 45(2), 203-212.

Koller, D.M., Myers, A.B., Lorenz, D., \& Godambe, S.A. (2007). Effectiveness of oxycodone, ibuprofen, or the combination in the initial management of orthopedic injury-related pain in children. Pediatric Emergency Care, 23(9), 627-633.

Kröner-Herwig, B., Morris, L., Heinrich, M., Gassmann, J., \& Vath, N. (2009) Agreement of parents an children on characteristics of pediatric headache, other pains, somatic symptoms, and depressive symptoms in an epidemiologic study. Clinical Journal of Pain, 25(1), 58-64.

Langer, S.L., Romano, J.M., Levy, R.L., Walker, L.S., \& Whitehead, W.E. (2009). Catastrophizing and parental response to child symptom complaints. Children's Health Care, 38, 169 - 184. doi: 10.1080/02739610903038750

Larson, R.W., Richards, M.H., Moneta, G., Holmbeck, G., \& Duckett, E. (1996). Changes in adolescents' daily interactions with their families from ages 10 to 18 : Disengagement and transformation. Developmental Psychology, 32(4), 744-754.

Lim, A., Cranswick, N., Skull, S., \& South, M. (2005). Survey of complementary and alternative medicine use at a tertiary children's hospital. Journal of Paediatrics and Child Health, 41, 424-427.

Loman, D.G. (2003). The use of complementary and alternative health care practices among children. Journal of Pediatric Health Care, 17, 58-63.

Lorenc, A., Ilan-Clarke, Y., Robinson, N., \& Blair, M. (2009). How parents choose to use CAM: a systematic review of theoretical models. BMC Complementary and Alternative Medicine, 9, 9-20.

Lynch-Jordan, A.M., Kashikar-Zuck, S., \& Goldschneider, K.R. (2010). Parent perceptions of adolescent pain expression: The adolescent pain behavior questionnaire. Pain, 151(3), 834-842.

Madsen, H., Andersen, S., Nielsen, GR., Dolmer, BS., Host, A., \& Damkier, A. (2003). Use of complementary/alternative medicine among paediatric patients. European Journal of Pediatrics, 162, 334-341. doi: 10.1007/s00431-003-1180-4

Maiman, L.A., Becker, M.H., \& Katlic, A.W. (1986). Correlates of mothers' use of medications for their children. Social Science \& Medicine, 22(1), 41-51.

Mathews, L. (2011). Pain in children: Neglected, unaddressed and mismanaged. Indian Journal of Palliative Care, Supplement, S70 - S73. 
McCracken, L.M., Hoskins, J., \& Eccleston, C. (2006). Concerns about medication and medication use in chronic pain. The Journal of Pain, 9(10), 726-734. doi: 10.1016/j.jpain.2006.02.014

McGrath, P. A. (1990). Chapter 5. Nonpharmacological methods for alleviating children's pain In Pain in children: nature, assessment, and treatment. (pp. 132 172). New York: The Guildford Press.

McGrath, P.J. (1996). Attitudes and beliefs about medication and pain management in children. Journal of Palliative Care, 12(3), 46-50.

Melamed, B.G. \& Bush, J.P. (1985). Family factors in children with acute illness. In D.C. Turk \& R.D. Kerns (Eds.), Health, illness, and families: A life-span perspective (pp. 183-219). New York: John Wiley \& Sons.

Moon, E.C., Chambers, C.T., Larochette, A., Hayton, K., Craig, K.D., \& McGrath, P.J. (2008). Sex differences in parent and child pain ratings during an experimental child pain task. Pain Research \& Management, 13(3), 225-230.

Moon, E.C., Chambers, C.T., \& McGrath, P.J. (2011). "He says, she says": A comparison of fathers' and mothers' verbal behavior during child cold pressor pain. The Journal of Pain, 12(11), 1174-1181.

Morton, N.S. (1998). Prevention and control of pain in children. Pain Reviews, 5, 1-15.

Nahin, R.L., Barnes, P.M., Stussman, B.J., \& Bloom, B. (2009). Costs of complementary and alternative medicine (CAM) and frequency of visits to CAM practitioners: United States, 2007. National Health Statistics Reports, 18, 1-16.

Neill, S.J. (2000). Acute childhood illness at home: The parents' perspective. Journal of Advanced Nursing, 31(4), 821-832.

Osman, A., Barrios, F.X., Kopper, B.A., Hauptmann, W., Jones, J., \& O’Neill, E. (1997). Factor structure, reliability, and validity of the Pain Catastrophizing Scale. Journal of Behavioral Medicine, 20(6), 589-605.

Pain Management Guideline Panel. (1992). Clinicians' quick reference guide to acute pain management in infants, children and adolescents: Operative and medical procedures. Journal of Pain and Symptom Management, 7(4), 229-242.

Pachter, L. M., Sumner, T., Fontan, A., Sneed, M., \& Bernstein, B. A. (1998). Hom based therapies for the common cold among European American and ethnic minority families. Archives of Pediatrics and Adolescent Medicine, 152, 1083 1088.

Palermo, T.M. (2000). Impact of recurrent and chronic pain on child and family daily functioning: A critical review of the literature. Developmental and Behavioral Pediatrics, 21(1), 58-69.

Palermo, T.M. \& Chambers, C.T. (2005). Parent and family factors in pediatric chronic pain and disability: An integrative approach. Pain, 119, 1-4.

Pederson, C., \& Harbaugh, B.L. (1995). Nurses' use of nonpharmacologic techniques with hospitalized children. Issues of Comprehensive Pediatric Nursing, 18, 91 109.

Perquin, C.W., Hazebroek-Kampschreur, A.A.J.M., Hunfeld, J.A.M., Bohnen, A.M., van Suijlekom-Smit, L.W.A., Passchier, J., \& van der Wouden, J.C. (2000). Pain in children and adolescents: A common experience. Pain, 87, 51-58.

Palmer, D.L., Berg, C.A., Butler, J., Fortenberry, K., Murray, M., Lindsay, R., \&...Wiebe, D.J. (2009). Mothers', fathers' and children's perceptions of parental 
diabetes responsibility in adolescence: Examining the roles of age, pubertal status, and efficacy. Journal of Pediatric Psychology, 34(2), 195-204.

Phillips, K.A., Morrison, K.R., Andersen, R., \& Aday, L.A. (1998). Understanding the context of healthcare utilization: Assessing environmental and provider-related variables in the behavioral model of utilization. HSR: Health Services Research, 33(3), 571-596.

Piker (2011) Balancing liberation and protection: A moderate approach to adolescent health care decision-making. Bioethics, 25(4), 202 - 208. doi: 10.1111/j.1467 8519.2009.01754.x

Pillai Riddell, R.R., Racine, N., Turcotte, K., Uman, L.S., Horton, R., Osmun, .D.,...Lisi, D. (2011). Nonpharmacological management of procedural pain in infants and young children: An abridged Cochrane review. Pain Research \& Management, 16(5), $321-330$.

Pinzon, J.L., Jacobson, K., \& Reiss, J. (2004). Say goodbye and say hello: The transition from pediatric to adult gastroenterology. Canadian Journal of Gastroenterology, 18(12), 735-742.

Pölkki, T., Vehviläinen-Julkunen, K., \& Pietilä, A. (2001). Nonpharmacological methods in relieving children's postoperative pain: a survey on hospital nurses in Finland. Journal of Advance Nursing, 34(4), 483-492.

Pölkki, T., Vehviläinen-Julkunen, K., \& Pietilä, A. (2002). Parents' roles in using non pharmacological methods in their child's postoperative pain alleviation. Journal of Clinical Nursing, 11, 526-536.

Pölkki, T., Pietilä, A., \& Vehviläinen-Julkunen, K. (2003). Hospitalized children's descriptions of their experiences with postsurgical pain relieving methods. International Journal of Nursing Studies, 40, 33-44.

Price, A., Ong, J., Isedale, G., \& Mackellar, C. (2011). Documenting and treating acute pain in children. Emergency Nurse, 19(3), 18-20.

Robinson, N., Lorenc, A., \& Blair, M. (2009). Developing a decision-making model on traditional and complementary medicine use for children. European Journal of Integrative Medicine, 1, 43-50.

Rolland, J.S. (1994). Families, Illness, and Disability: An integrative treatment model. New York: BasicBooks.

Rony, R.Y.Z., Fortier, M.A., Chorney, J.M., Perret, D., \& Kain, Z.N. (2010). Parental postoperative pain management: Attitudes, assessment, and management, Pediatrics, 125, e1372-e1378. doi: 10.1542/peds.2009-2632.

Roter, D.L., \& Hall, J.A. (1994). Strategies for enhancing patient adherence to medical recommendations. JAMA, 271(1), 80.

Rusy, L.M., \& Weisman, S.J. (2000). Complementary therapies for acute pediatric pain management. Pediatric Clinics of North America, 47(3), 589-599. doi: 10.1016/S0031-3955\%2805\%2970227-3

Sawni, A., Ragothaman, R., Thomas, R. L., \& Mahajan, P. (2007). The use of complementary/alternative therapies among children attending and urban pediatric emergency department. Clinical Pediatrics, 46, 36-41.

Sawni-Sikand, A. Schubiner, H., \& Thomas, R.L. (2002). Use of complementary/alternative therapies among children in primary care pediatrics. Ambulatory Pediatrics, 2, 99-103. 
Schecter, N.L. (1989). The undertreatment of pain in children: An overview. Pediatric Clinics of North America, 36(4), 781-794.

Simon, H.K., \& Weinkle, D.A. (1997). Over-the-counter medications. Archives of Pediatrics \& Adolescent Medicine, 151, 645-656.

Simpson, N., \& Roman, K. (2001). Complementary medicine use in children: extent and reasons. A population-based study. British Journal of General Practice, 914-916.

Sirois, F.M. (1998). An investigation of the health beliefs and motivations of complementary medicine clients. (Master's thesis). Retrieved from www.nlc.bnc.ca

Sirois, F.M. \& Gick, M.L. (2002). An investigation of the health beliefs and motivations of complementary medicine clients. Social Science \& Medicine, 55, 1025-1037.

Smetana, J.G., Metzger, A., Gettman, D.C., \& Campione-Barr, N. (2006). Disclosure and secrecy in adolescent-parent relationships. Child Development, 77(1), 201-217.

Spigelblatt, L., Laîné-Ammara, G., Pless, B., \& Guyver, A. (1994). The use of alternative medicine by children. Pediatrics, 94(6), 811-814.

SPSS Inc. (2008). SPSS Base 17.0 for Windows User's Guide. SPSS Inc., Chicago, IL.

Sullivan, M.J.L., Bishop, S.R., \& Pivik, J. (1995). The Pain Catastrophizing Scale: Development and validation. Psychological Assessment, 7(4), 524 - 532.

Sullivan, M.J.L., Martel, M.O., Tripp, D.A., Savard, A., \& Crombez, G. (2006). Catastrophic thinking and heightened perception of pain in others. Pain, 123, 37 44.

Sullivan, M.J.L., Thorn, B., Haythornthwaite, J.A., Keefe, F., Martin, M., Bradley, L.A., \& Lefebvre, J.C. (2001). Theoretical perspectives on the relation between catastrophizing and pain. The Clinical Journal of Pain, 17,52 - 64.

Taddio, A., Shah, V., Gilbert-MacLeod, C., \& Katz, J. (2002). Conditioning and Hyperalgesia in Newborns Exposed to Repeated Heel Lances. JAMA, 288, 857 861.

Tasso, K., \& Behar-Horenstein, L. S. (2004). Patients' perceptions of pain management and use of coping strategies. Hospital Topics, 82(4), 10-19

Upchurch, D.M., Burke, A., Dye, C., Chyu, L., Kusunoki, Y., \& Greendale, G.A. (2008). A sociobehavioral model of acupuncture use, patterns, and satisfaction among women in the United States, 2002. Women's Health Issues, 18, 62-71.

Vervoort, T., Goubert, L., Eccleston, C., Bijttebier, P., \& Crombez, G. (2006). Catastrophic Thinking About Pain is Independently Associated with Pain Severity, Disability, and Somatic Complaints in School Children and Children with Chronic Pain. Journal of Pediatric Psychology, 31(7), 674-683. doi:10.1093/jpepsy/jsj059

Vlieger, A. M., Blink, M., Tromp, E., \& Benninga, M.A. (2008). Use of complementary and alternative medicine by pediatric patients with functional and organic gastrointestinal diseases: result from a multicenter survey. Pediatrics, 122(2), e446-e451. doi: 10.1542/peds.2008-0266

Walco, G.A., Cassiday, R.C., \& Schecter, N.L. (1991). Pain, hurt and harm: The ethics of pain control in infants and children. The New England Journal of Medicine, 331(8), 541-543.

Walker, L.S. \& Zeman, J.L. (1992). Parental response to child illness behavior. Journal of Pediatric Psychology, 17(1), 49-71. 
Wamboldt, F.S., Bender, B.G., \& Rankin, A.E. (2011). Adolescent decision-making about use of inhaled asthma controller medication: Results from focus groups with participants from a prior longitudinal study. Journal of Asthma, 48, 741-750.

Wilson, M.E. \& Helgadóttir, H.L. (2006). Patterns of pain and analgesic use in 3- to 7 year-old children after tonsillectomy. Pain Management Nursing, 7(4), 159 - 166.

Wilson, J.E., \& Pendleton, J.M. (1989). Oligoanalgesia in the emergency department. American Journal of Emergency Medicine, 7, 620-623.

Wilson, D.K., St. George, S.M., \& Zarrett, N. (2010). Developmental influences in understanding child and adolescent health behaviors. In J.M. Suls, K.W. Davidson, \& R.M. Kaplan (Eds.), Handbook of health psychology and behavioral medicine easurement of pain in infants and children (pp. 133-146). New York: The Guilford Press.

Wray-Lake, L., Crouter, A.C., \& McHale, S.M. (2010). Developmental patterns in decision making autonomy across middle childhood and adolescence: European American parents' perspectives. Child Development, 81(2), 636-651.

Young, K.D. (2005). Pediatric Procedural Pain. Annals of Emergency Medicine, 45(2), $160-171$. 
Figure 1. Types of pain treatments and providers.

\begin{tabular}{|l|l|l|}
\hline & \multicolumn{2}{|c|}{ Type of Pain Treatment } \\
& \multicolumn{2}{|c|}{ Pharmacological } \\
Non-Pharmacological \\
\hline $\begin{array}{l}\text { Medical/Professional } \\
\text { Provider }\end{array}$ & $\begin{array}{l}\text { Conventional/Western } \\
\text { medicine }\end{array}$ & $\begin{array}{l}\text { Complementary and } \\
\text { alternative medicine }\end{array}$ \\
\hline Parent/Self Provided & $\begin{array}{l}\text { Over-the-counter } \\
\text { medications }\end{array}$ & $\begin{array}{l}\text { Non-pharmacological } \\
\text { techniques }\end{array}$ \\
\hline
\end{tabular}


Figure 2. Modified Andersen's sociobehavioral model.

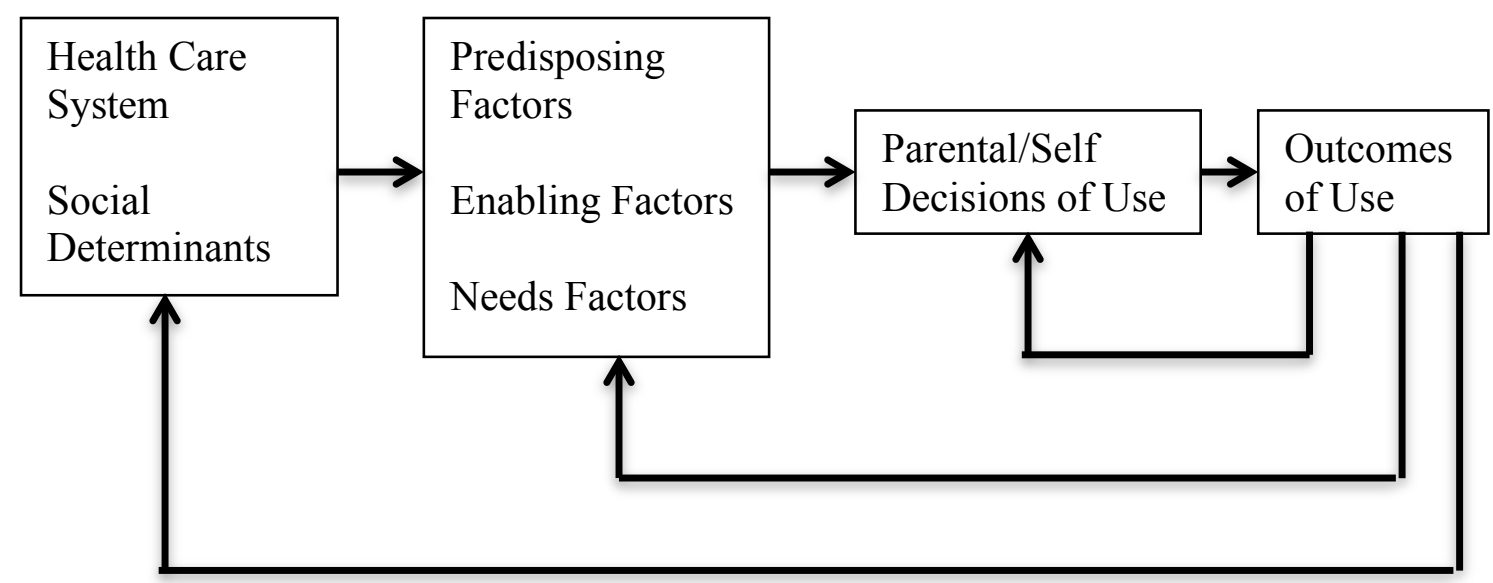


Figure 3. Trends in use of self-administration of pharmacological techniques based on children's age.

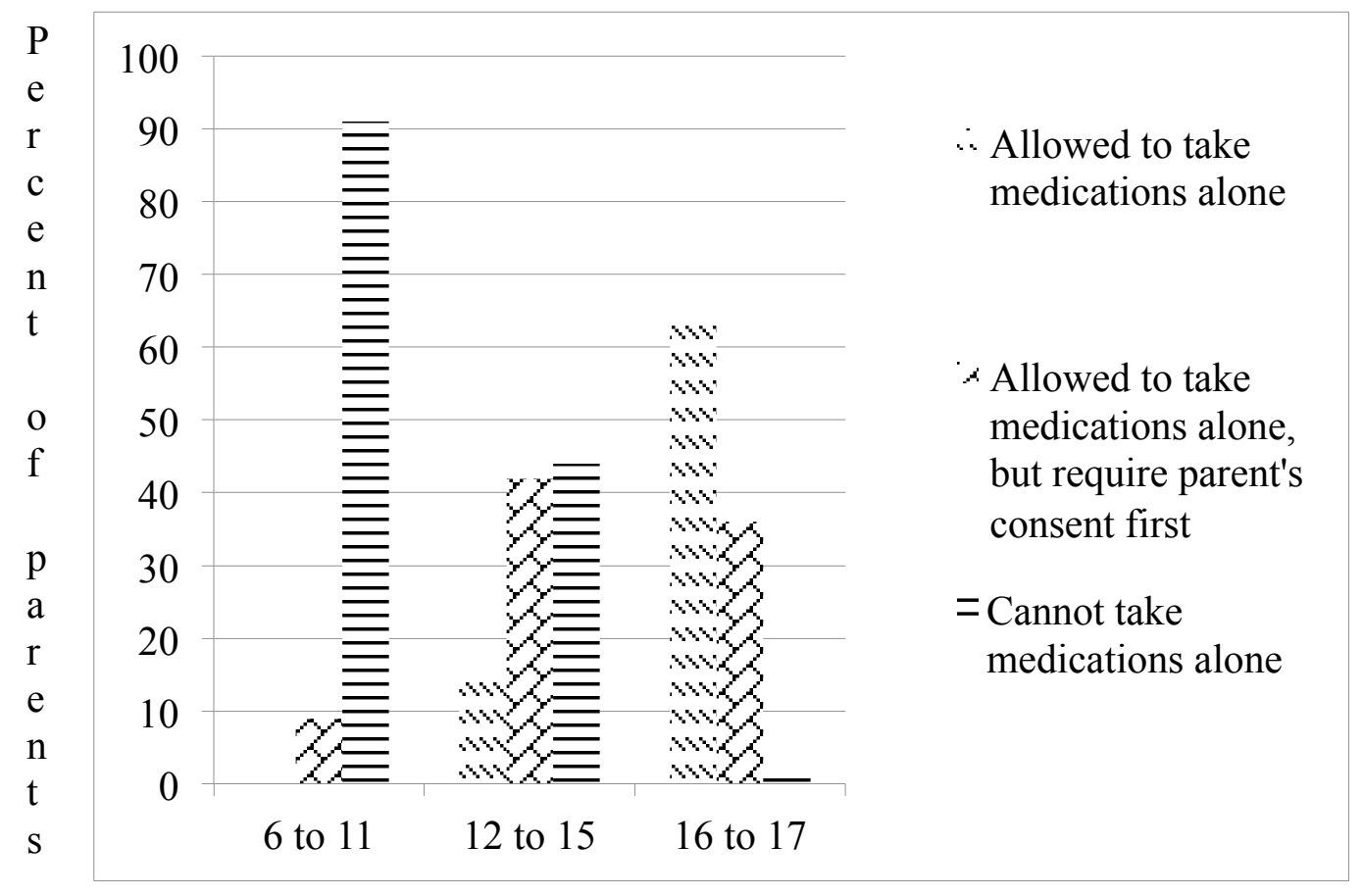

Child's age (years) 
Figure 4. Trends in use of self-administration of non-pharmacological techniques based on children's age.

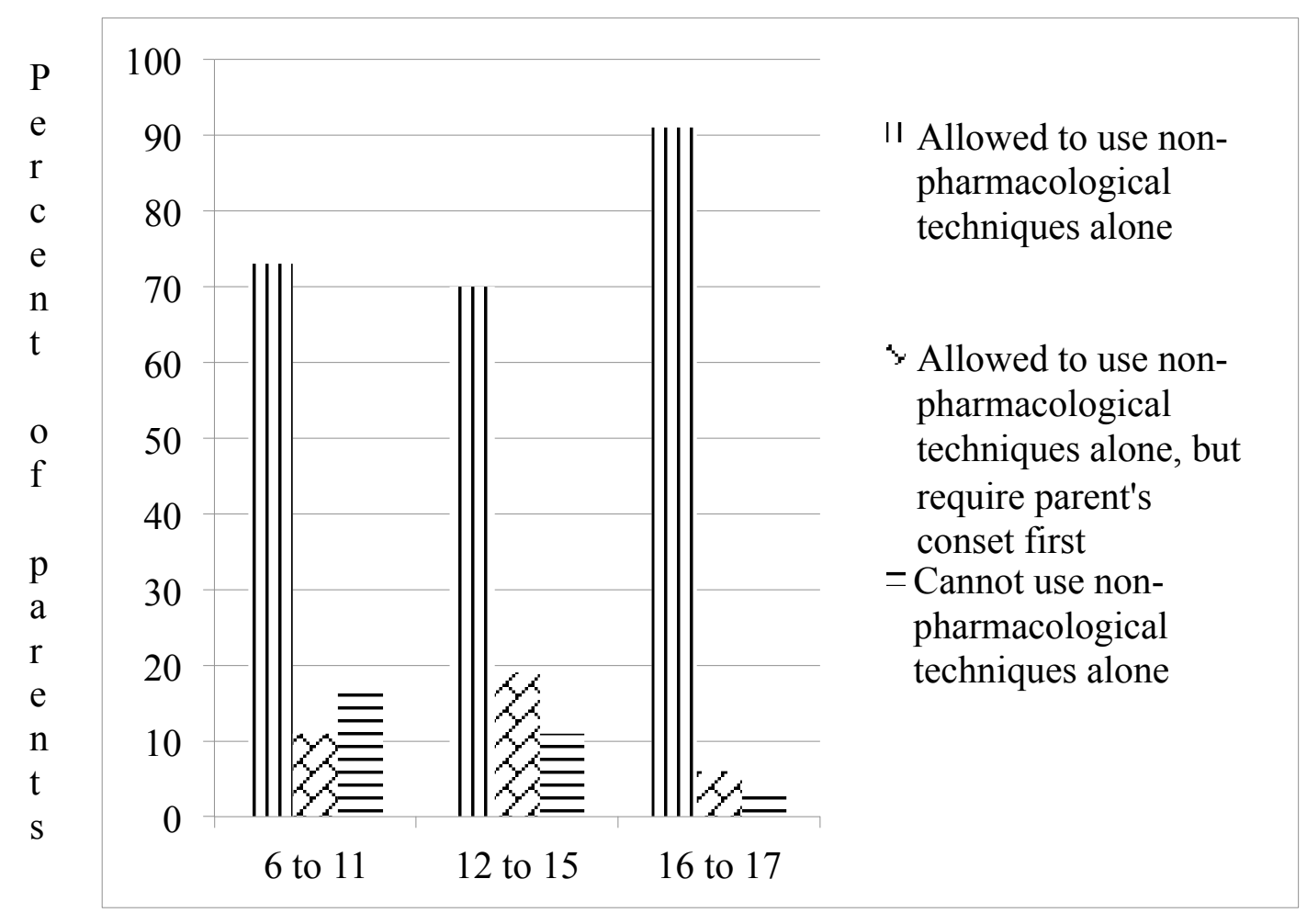

Child's age (years) 
Figure 5. Proposed model for current factors leading to parents' treatment decisions for childhood pain at home.

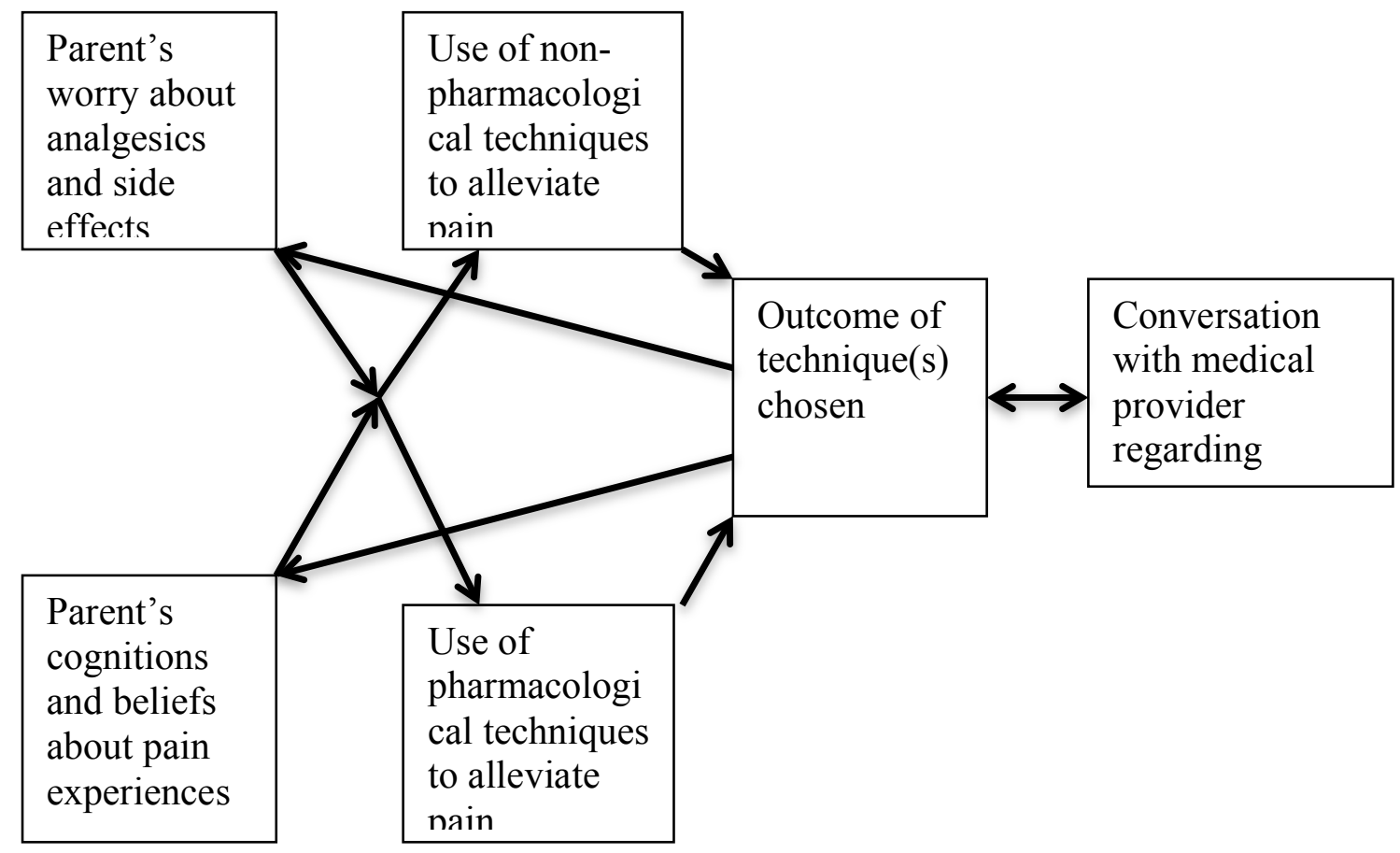


Figure 6. Proposed model for future factors leading to parents' treatment decisions and reduced oliganalgesia and increased effective treatment of childhood pain at home.

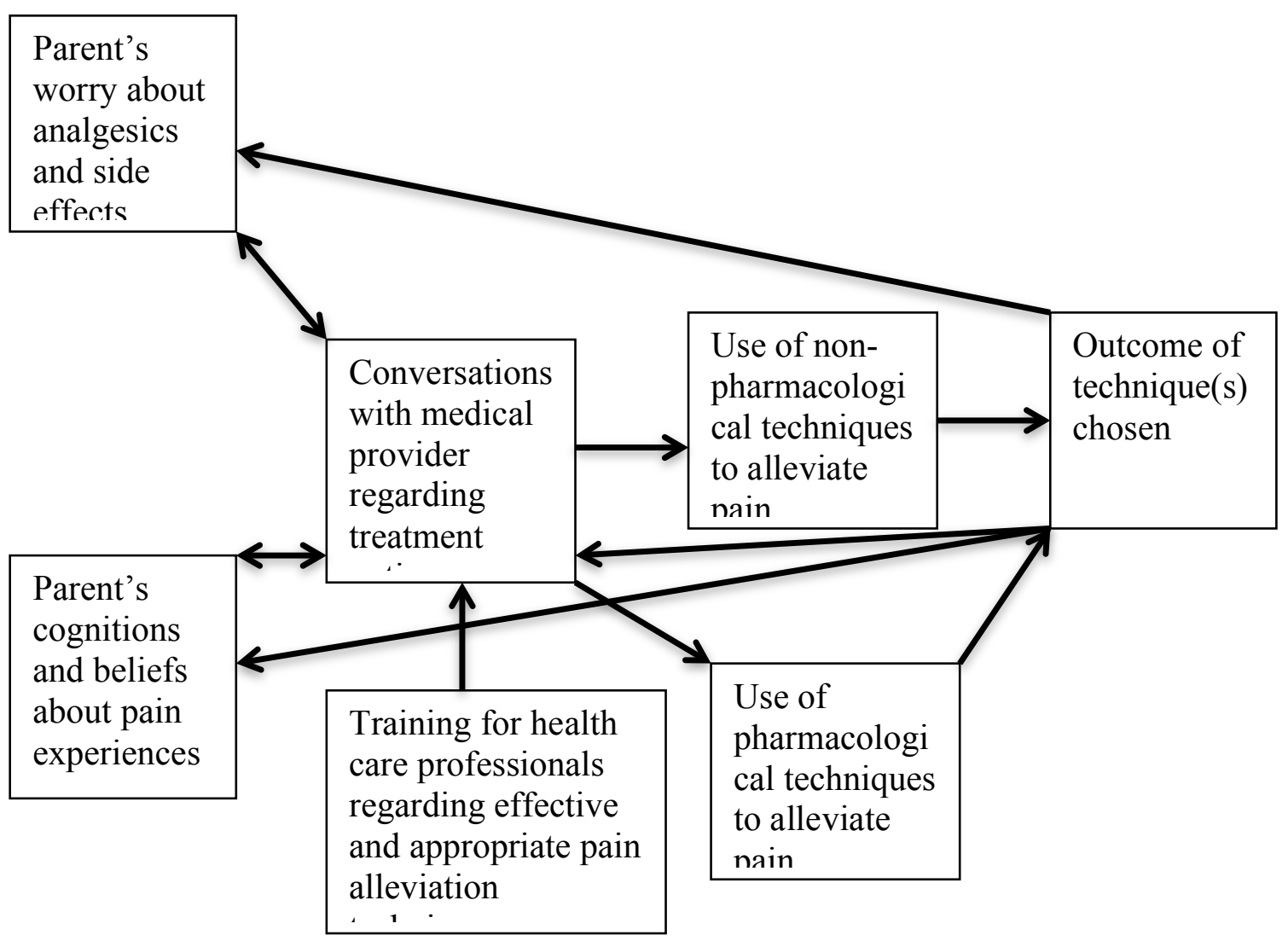


Table 1.

Frequency of Children's Pain Experiences

\begin{tabular}{lll} 
Frequency & Percentage & Number of Children \\
\hline Never & 12.3 & 92 \\
Less than once a month & 49.5 & 369 \\
Monthly & 20.3 & 151 \\
Weekly & 11.7 & 87 \\
Several times a week & 5.0 & 37 \\
Every day & 1.2 & 9 \\
\hline
\end{tabular}


Table 2.

Children's Pain Locations

\begin{tabular}{llll} 
Location & $\begin{array}{l}\text { Percentage in Entire } \\
\text { Sample }\end{array}$ & $\begin{array}{l}\text { Percentage in } \\
\text { Higher Pain } \\
\text { Frequency } \\
\text { Sample }\end{array}$ & $\begin{array}{l}\text { Number of } \\
\text { Children in Higher } \\
\text { Pain Frequency } \\
\text { Sample }\end{array}$ \\
\hline Stomach & 30.7 & 38.4 & 109 \\
Head & 29.6 & 39.1 & 111 \\
Muscles & 18.0 & 22.5 & 64 \\
Bones/joints & 14.9 & 20.4 & 58 \\
Back/shoulders & 11.2 & 16.9 & 48 \\
Mouth/throat & 11.0 & 10.2 & 29 \\
Elbows/knees & 9.4 & 14.4 & 41 \\
Ears & 5.0 & 4.9 & 14 \\
Eyes & 2.0 & 2.8 & 8 \\
\hline
\end{tabular}


Table 3.

Non-pharmacological Techniques Provided

\begin{tabular}{llll}
$\begin{array}{l}\text { Non-pharmacological } \\
\text { Technique }\end{array}$ & $\begin{array}{l}\text { Percentage in Entire } \\
\text { Sample }\end{array}$ & $\begin{array}{l}\text { Percentage in } \\
\text { Higher Pain } \\
\text { Frequency } \\
\text { Sample }\end{array}$ & $\begin{array}{l}\text { Number of } \\
\text { Parents in Higher } \\
\text { Pain Frequency } \\
\text { Sample }\end{array}$ \\
\hline Sleep & 68.0 & 69.7 & 198 \\
Ice & 63.5 & 62.7 & 178 \\
Comfort & 54.1 & 57.4 & 163 \\
Rub/massage & 51.1 & 57.4 & 163 \\
Bath & 49.6 & 51.1 & 145 \\
Give liquids & 48.5 & 52.8 & 150 \\
Warmth & 44.0 & 49.3 & 140 \\
Restrict their activity & 42.5 & 47.2 & 134 \\
Giving child attention & 33.7 & 36.3 & 103 \\
Distraction & 30.7 & 36.6 & 104 \\
Breathing/calming exercise & 21.7 & 26.8 & 76 \\
Tell them to "suck it up" & 17.6 & 24.6 & 70 \\
TENS unit & 0.7 & 1.1 & 3 \\
\hline
\end{tabular}


Table 4.

Descriptive Statistics of Children's Age Categories for Higher Frequency Pain Group

\begin{tabular}{llll} 
Age Category (years) & $\begin{array}{l}\text { Number of } \\
\text { Children }\end{array}$ & Mean & Standard Deviation \\
\hline 6 to 11 & 107 & 8.24 & 1.72 \\
12 to 15 & 102 & 13.34 & 1.25 \\
16 to 17 & 74 & 16.54 & 0.50 \\
11 and younger & 107 & 8.24 & 1.72 \\
12 and older & 176 & 14.69 & 1.87 \\
\hline
\end{tabular}




\section{Appendix}

\section{Relevant SurveyMonkey.com Questions}

I certify that I am at least 18 years old and that I am giving my voluntary consent to be a participant in this project.

○ Yes

○ No

Thank you for agreeing to take part in this survey. Please provide the following information so that we can describe the participants.

1. What are the initials and number of the student who asked you to complete the survey?

2. What is your gender?

○ Female

- Male

3. What is your current age?

4. What is your marital status?

- Single, never married

- Married

○ Separated

- Divorced

$\circ$ Widowed

5. How many years of education do you have?

- 6 or fewer

$\circ 7$

○ 8

$\circ 9$

- 10

○ 11

- 12 High School Graduate

○ 13

- 14 Associates Degree

○ 15

- 16 College Degree

○ 17

- 18 Masters Degree

○ 19

- 20 or more Doctoral Degree 
6. What race/ethnicity do you consider yourself to be?
o Black
- Asian
- Caucasian/White
- Latino/a
- Native American
o Mixed
O Other (please specify)

7. What religion are you?
○ Catholic
- Protestant
○ Jewish
- Muslim
○ Buddhist
- Hindu
- No Religion
O Other (please specify)

8. How many children do you have?
○ 1
○ 2
○ 3
$\circ 4$
○ 5
○ 6
○ 7
- 8 or more

9. How old is your oldest child?

10. How old is your youngest child?

11. What is the city and state of your primary residence?

12. How would you describe your typical philosophy on social issues?
○ Very Liberal
- Liberal
- Moderate
- Conservative
- Very Conservative 
Several of the sections that follow ask you to answer based on your OLDEST child who is between 12 and 17 years old.

Please give us some general information here about that child.

1. What is this child's gender?
○ Female
○ Male

2. How old is this child?
○ 12
○ 13
○ 14
○ 15
○ 16
○ 17

3. What is this child's birth order?
○ Only child
- Oldest child
○ Middle child
$\circ$ Youngest child

4. Does your child have a primary or regular medical doctor that they see?
- Yes, a pediatrician
- Yes, a family medicine doctor
- Yes, a doctor with another specialty
- Yes, a nurse practitioner
o No

5. If your child has a primary or regular doctor, what is the doctor's gender?
- Female
○ Male

6. If your child has a primary or regular doctor, how long has he/she been taking care of your child?
- Less than a year
○ 1 to 2 years
○ 3 to 5 years
○ 6 to 9 years
○ 10 years or more 
7. If your child has a primary or regular doctor, how satisfied have you been with the care they have received?

$\begin{array}{ll}\circ & 1 \text { Not At All Satisfied } \\ \circ & 2 \\ \circ & 3 \\ \circ & 4 \\ \circ & 5 \\ \circ & 6 \\ \circ & 7 \\ \circ & 8 \\ \circ & 9 \\ \circ & 10 \text { Very Satisfied }\end{array}$

8. If your child has a primary or regular doctor, how well do you like the doctor?
○ 1 Not At All
○ 2
○ 3
○ 4
$\circ 5$
○ 6
$\circ 7$
○ 8
○ 9
○ 10 Like very much 
Please think about your oldest child between 12 and 17 as you answer the questions below.

1. On average, how often does your child report or show pain?

- Every day

- Several times a week

○ Weekly

○ Monthly

- Less than once a month

- Never

2. Where does he/she usually experience pain? (check all that apply).
○ Back/Shoulders
- Bones/Joints
- Ears
- Elbows/Knees
- Eyes
○ Head
○ Muscles
○ Mouth/Throat
○ Stomach
Other (please specify)

3. How comfortable do you feel giving him/her pain medication?

- Not at all comfortable

- Somewhat comfortable

○ Very comfortable

4. Do you worry about giving pain medication?
- Yes
o No

5. Which of the following negative consequences (if any) do you worry about when deciding to give pain medication? (check all that apply).
o Overuse
- Addiction
- Drowsiness
○ Nausea
$\circ$ Other (please specify) 
6. Which of the following pain medications HAVE YOU GIVEN to your child when he/she was in pain? (check all that apply).

○ Tylenol/acetaminophen

- Aspirin

- Advil/Motrin/ibuprofen

○ Opiates/narcotics (e.g., codeine, morphine)

O Other (please specify)

7. Which of the following pain medications HAVE YOU AVOIDED GIVING to your child when he/she was in pain? (check all that apply).

o Tylenol/acetaminophen

- Aspirin

- Advil/Motrin/ibuprofen

○ Opiates/narcotics (e.g., codeine, morphine)

O Other (please specify)

8. Is your child allowed to take pain medications at home like tylenol or ibuprofen on their own?

- Yes, he/she can decide they need it and take it on their own.

- Yes, but he/she has to check with a parent first.

$\circ \mathrm{No}$, he/she has to get the medicine from a parent.

9. Which of the following are reasons you have decided to give pain medications when you have decided to do so?

○ High level of pain

- Pain lasted too long

- Unable to sleep due to pain

- Emotionally upset by pain

o Unable to go to school or do schoolwork

$\circ$ Unable to eat due to pain

- Wanted to stop pain before it got worse

- Child asked for medicine

○ Other (please specify) 
10. Which of the following (if any) are reasons that you have decided not to give pain medications in the past? (check all that apply).

○ You thought the pain would pass quickly

- You thought the pain was stress related

- You used non-medication approaches

- You were not sure the medication was safe.

- You felt you did not know enough about the medication

- Your child was allergic to the medication

- You were not sure about the right dosage

- You thought he/she was exaggerating the pain

- You thought he/she was faking the pain

- None

O Other (please specify)

11. Non-medication approaches to pain management include a number of different comfort measures such as massage, sleep, warmth, ice, and distracting your child from the pain. Have you ever used any techniques like this with this child?

$\begin{array}{ll}\circ & \text { Yes } \\ \circ & \text { No }\end{array}$

12. Other than pain medications, which of the following techniques (if any) have you used to help your child manage pain? (check all that apply).
○ Bath
○ Rub/massage
- Sleep
○ Comfort
- Tell them to "suck it up"
○ Ice
○ Giving child attention
- Restrict their activity
- Give liquids
- Breathing/calming exercises
○ Warmth
- Distraction
- TENS unit
O Other (please specify) 
13. Which of these non-medication approaches to pain management have you used with your child most often?

○ Bath

- Rub/massage

○ Sleep

○ Comfort

- Tell them to "suck it up"

○ Ice

- Giving child attention

- Restrict their activity

$\circ$ Give liquids

○ Breathing/calming exercises

- Warmth

- Distraction

- TENS unit

O Other (please specify)

14. When you have used non-medication approaches, have you typically used them alone or along with pain medications?

○ Use non-medication approaches alone, without medication.

- Use medication and non-medication approaches together.

○ Try medication first, then use non-medication approaches as needed.

- Try non-medication approaches first, then use medication as needed.

○ No typical pattern.

How did you decide on this approach? 
1. How did you learn how to use [the most often used non-medication approach] for pain management? (check all that apply).

$\circ$ Learned from own personal experience.

- Learned from my professional experience.

- Learned from my own parents.

- Learned from experience with this or other children.

- Learned from a healthcare provider.

- Read about in a book or magazine.

- Read about on the internet.

O Other (please specify)

2. Is your child allowed to use [the most often used non-medication approach] for pain management at home on their own?

○ Yes, he/she can decide they need it and use it on their own.

- Yes, but he/she has to check with a parent first.

○ No, he/she needs to do with or get from a parent.

3. Have you talked with your pediatrician about appropriate uses of pain medications?

o Yes

o No

4. If you have talked with your pediatrician about pain medications, who initiated that discussion?

I or another family member did.

- Pediatrician did.

o Don't remember.

5. Have you talked with your pediatrician about non-medication techniques for pain management?

○ Yes

o No

6. If you have talked with your pediatrician about non-medication techniques, who initiated that discussion?

- I or another family member did.

- Pediatrician did.

- Don't remember. 


\section{PCS-P}

Everyone experiences painful situations at some point in their lives. We are interested in the thoughts and feelings that you have when your child is in pain. Listed below are 13 statements describing different thoughts and feelings that may be associated with pain. For each statement, please indicate how much you have that thought or feeling when your child is in pain.

○ Not at all

○ Mildly

- Moderately

- Severely

○ Extremely

1. When my child has pain, I worry all the time about whether the pain will end.

2. When my child has pain, I feel I can't go on.

3. When my child has pain, it is terrible and I think it is never going to get any better.

4. When my child has pain, it is awful for me and I think I won't be able to cope with it.

5. When my child has pain, I become afraid that the pain will get worse.

6. When my child has pain, I feel I cannot stand it anymore.

7. When my child has pain, I keep thinking of other painful times.

8. When my child has pain, I anxiously want the pain to go away.

9. When my child has pain, I cannot seem to get it out of my mind.

10. When my child has pain, I keep thinking about how much it hurts.

11. When my child has pain, I keep thinking about how badly I want the pain to stop.

12. When my child has pain, there's nothing I can do to reduce the level of pain.

13. When my child has pain, I wonder whether something serious may happen.

Thank you for your help with this class project. 


\section{CURRICULUM VITA}

Ayala Y. Gorodzinsky

Place of birth: London, Ontario

Education

B.Sc., McMaster University, June 2004

Major: Psychology

M.S., University of Wisconsin-Milwaukee, December 2010

Dissertation Title: Parents' Treatment of Their Children's Pain at Home:

Pharmacological and Non-pharmacological Approaches

Honors and Awards

Trainee Member, Pain in Child Health Consortium, funded by the Mayday Fund and under sponsorship of the Canadian Institutes of Health Research (CIHR)

Principal investigator mentor: Patrick McGrath, Ph.D.

2007

First Place Graduate Student Research Award, Wisconsin

Psychological Association Conference: Parents' perceived risk of and preparation for avian influenza pandemic

Clinical Experience

September 2011

to Present

August 2011

to Present

September 2010

to May 2012
Trainee Supervisor Assistant, UWM Psychology Clinic University of Wisconsin-Milwaukee

Milwaukee, WI.

Supervisor: Gwynne O. Kohl, Ph.D.

Assistant to the Clinic Director, UWM Psychology Clinic University of Wisconsin-Milwaukee

Milwaukee, WI.

Clinic Director and supervisor: Jonathan Kanter, Ph.D.

Practicum Student, Child and Adolescent Day Treatment Rogers Memorial Hospital

Milwaukee, WI.

Supervisor: Nancy Goranson, Ph.D.

July 2010

Assessment Assistant, Child Neurodevelopment Research 
to January 2012

September 2009

to September 2011

September 2007

to May 2008
Laboratory

University of Wisconsin-Milwaukee

Milwaukee, WI.

Supervisor: Bonnie Klein-Tasman, Ph.D.

Trainee in Clinical Psychology, University of Wisconsin

Milwaukee

Milwaukee, WI.

Supervisors: Gwynne O. Kohl, Ph.D. and Robyn Ridley, Ph.D.

Clinical and Assessment Practicum Experience, University of Wisconsin-Milwaukee Psychology Clinic

Milwaukee, WI.

Supervisors: Bonnie Klein Tasman, Ph.D., David C. Osmon, Ph.D., ABPP and W. Hobart Davies, Ph.D.

Research Experience

October 2008 to Present

January 2009 to May 2012

January 2007 to May 2012
Sibling Relationships Chronic Pain Study, Research Coordinator

Milwaukee, WI.

Conceptualized, conducted and analyzed research assessing adolescents' perceptions of their family relationships when one sibling has chronic pain. Led and supervised other students in qualitative data analysis. Recruited participants, conducted interviews with participants and transcription of interviews. Supervisors: Keri Hainsworth, Ph.D. and W. Hobart Davies, Ph.D.

\author{
Parents' Impressions of Treatment at a Multidisciplinary \\ Tertiary Chronic Pain Clinic \\ Research Assistant \\ University of Wisconsin-Milwaukee \\ Milwaukee, WI. \\ Supervisor: Anthony A. Hains, Ph.D. and Steven J. Weisman, \\ M.D.
}

Chronic Pain Psychosocial Research Team, Children's Hospital of Wisconsin

Milwaukee, WI.

Supervisors: W. Hobart Davies, Ph.D. and Keri Hainsworth, Ph.D. Children's Hospital of Wisconsin 
Journal Publications

Gorodzinsky, A.Y., Jessica M. Bernacki, W. Hobart Davies, Amy L. Drendel \& Steven J. Weisman. (2012). Community parents' use of non-pharmacological techniques for pediatric pain management. Children's Health Care, 41(1):1-15, doi: 10.1080/02739615.2012.643286

Gorodzinsky, A.Y., Hainsworth, K.R. \& Weisman, S.J. (2011). School Functioning and Chronic Pain: A Review of Methods and Measures. Journal of Pediatric Psychology, 36(9), 991-1002. doi: 10.1093/jpepsy/jsr038

Tran, S.T., Gorodzinsky, A.Y. \& Davies, W.H. (2011). Predictors and barriers of H1N1 vaccination intention in healthy and high-risk children. Children's Health Care, 40(4), 269 - 281. doi: 10.1080/02739615.2011.617245

Newsletter publication

Davies, W.H., Holman, K.S., Gorodzinsky, A.Y., Clifford, L.M., \& Whelan, D.J. (2012). Mental Health Services Utilized by Families Adopting Special Needs Children. APA Children, Youth, and Family News.

Conference presentations

Gorodzinsky, A.Y., Davies, W.H., Heinze, S.T., Joseph, J.M., Medrano, G.R., Elftman, J., Anderson Khan, K., Hainsworth, K.R, \& Weisman, S.J. (2011, February). Adolescents' Perceptions of their Familial Relationships when a Sibling has Chronic Pain. Presentation given at The Annual Pediatric Behavioral Health Research Conference in Wauwatosa, WI.

Gorodzinsky, A.Y., Heinze, S.T. \& Davies, W.H. (2010, April). H1N1 Vaccinations Not Predicted by High-Risk Pediatrics Diagnoses. Presentation given at The Annual Graduate Student Research Symposium in Milwaukee, WI.

Posters and Published Abstracts:

International Meetings

Gorodzinsky, A.Y., Davies, W.H., Medrano, G.R., Tran, S.T., Bernacki, J.M., Burks, L.M., Feller, T.M., Anderson Khan, K., Ladwig, R.J., Hainsworth, K.R. \& Weisman, S.J. (2011, October). Changes in Familial Relationships Related to Pediatric Chronic Pain: Perspectives from Adolescent Patients and their Siblings. Poster presented at the International Forum on Pediatric Pain in White Point, Nova Scotia, Canada.

National Meetings 
Gorodzinsky, A.Y., Majewski, A.J., Mertens, C.M. \& Davies, W.H. (2011, April). Cosleeping behaviors in community parents: Implications for Child Protection. Poster presented at the National Conference in Child Health Psychology, San Antonio, TX.

Heinze, S.T., Gorodzinsky, A.Y., Drew, J.G. \& Davies, W.H. (2010, August). Parents' Perceptions of H1N1 Risk Predict Child Vaccinations. Poster presented at the 2010 APA Annual Convention in San Diego, CA.

Heinze, S.T., Medrano, G.R., Gorodzinsky, A.Y., Hainsworth, K.R. \& Weisman, S.J. (2010, April). Applying the Fear-Avoidance Model of Chronic Pain to a Pediatric Population. Poster presented at the Annual Meeting \& Scientific Sessions of the Society of Behavioral Medicine in Seattle, WA.

Gorodzinsky, A.Y., Joseph, J.M., Heinze, S.T., Simon, K., Drendel, A.L., \& Davies, W.H. (2009, October). Parents' Perceptions of Pharmacological and Nonpharmacological Techniques for Pain Control in Children. Poster presented at Annual Meeting for the Society for Developmental \& Behavioral Pediatrics, Portland, OR.

Joseph, J.M., Gorodzinsky, A.Y., Medrano, G.R., Drendel, A.L. \& Davies, W.H. (2009, October). How Do Parents Make Decisions About Analgesic Use? Examining the Impact of child Age and Parent Gender in a Community Sample. Poster presented at Annual Meeting for the Society for Developmental \& Behavioral Pediatrics, Portland, OR.

Gorodzinsky, A.Y., Joseph, J.M., Simon, K., Drendel, A.L., \& Davies, W.H. (2008, April). Parents' perceptions of pharmacological and non-pharmacological techniques for pain control in pre-school and early school-aged children. Poster presented at the National Conference in Child Health Psychology, Miami, FL.

Joseph, J.M., Gorodzinsky, A.Y., Sato, A.F., Drendel, A.L., Davies, W.H. (2008, April). Role of parent and child gender in the treatment of preschool and early school-age children's pain: Results from a community sample. Poster presented at the National Conference in Child Health Psychology, Miami, FL.

Simon, K., Sato, A.F., Gorodzinsky, A.Y., Hainsworth, K.R., Davies, W.H., Khan, K.A. \& Weisman, S.J. (2008, April). Pain catastrophizing and social support: The role of social consequences for youth with chronic pain. Poster presented at the National Conference in Child Health Psychology, Miami, FL.

Simon, K., Sato, A.F., Gorodzinsky, A.Y., Hainsworth, K.R., Khan, K.W., Weisman, S.J. \& Davies, W.H. (2008, April). Social consequences of pediatric chronic pain: Concordance of multiple informants. Poster presented at the National Conference in Child Health Psychology, Miami, FL. 
Regional Meetings

Gorodzinsky, A.Y., Drendel, A.L., \& Davies, W.H. (April, 2012). Parental Pain Catastrophizing Influences Decision Making Around Managing Children's Pain. Poster presentation at the Midwest Regional Conference on Pediatric Psychology in Milwaukee, WI.

Murphy, J.D., Gorodzinsky, A.Y., Drendel, A.L., Davies, W.H. (February, 2012). Autonomy When Administering Pain Alleviation Techniques Increases as Age Increases. Poster presented at the Annual Pediatric Behavioral Health Research Conference in Wauwatosa, WI.

Feller, T.M., Gorodzinsky A.Y., Medrano, G.R., Burks, L.M., Heinze, S.T., Joseph, J.M., \& Davies, W.H. (2011, April). Chronic pain and how it changes family relationships. Poster presentation at the Association of Graduate Students in Psychology Research Symposium in Milwaukee, WI.

Feller, T.M., Gorodzinsky A.Y., Medrano, G.R., Burks, L.M., Heinze, S.T., Joseph, J.M., \& Davies, W.H. (2011, March). Chronic pain and how it changes family relationships. Poster presentation at the Wisconsin Psychological Association Convention in Middleton, WI.

Gorodzinsky, A.Y., Majewski, A.J., Mertens, C.M. \& Davies, W.H. (2011, March). Cosleeping behaviors in community parents: Implications for Child Protection. Poster presentation at the Wisconsin Psychological Association Annual Convention in Middleton, WI.

Gorodzinsky, A.Y., Heinze, S.T., Joseph, J.M., Medrano, G.R., Elftman, J., Khan, K.A., Hainsworth, K.R., Weisman, S.J. \& Davies, W.H. (2010, October). Adolescents' Perceptions of their Relationship to a Sibling with Chronic Pain. Poster Presentation at The Kansas Conference in Clinical Child and Adolescent Psychology: Translating Research into Practice in Lawrence, KS.

Heinze, S.T., Gorodzinsky, A.Y. \& Davies. W.H. (2010, March). H1N1 Vaccination Behavior and Attitudes Not Predicted by High-Risk Pediatric Diagnosis. Poster presentation at the Wisconsin Psychological Association Annual Convention in Middleton, WI.

Gorodzinsky, A.Y., Heinze, S.T., Joseph, J.M., Medrano, G.R., Salamon, K.S., Khan, K.A., Hainsworth, K. (2010, February). Adolescents' perceptions of sibling relationships when their sibling has chronic pain. Poster presented at the Annual Pediatric Behavioral Health Research Conference in Wauwatosa, WI. 
Gorodzinsky, A.Y., Joseph, J.M., Jastrowski Mano, K.E., Holman, K.S. \& Davies, W.H. (2009, April). Relationship between global psychosocial functioning and pain-related school absence in youth. Poster presented at The Midwest Conference on Pediatric Psychology in Kansas City, MO.

Holman, K., Gorodzinsky, A.Y. \& Clifford, L. (2008, October). Mental health service utilization among special needs adoptive families. Poster presented at The Kansas Conference in Clinical Child and Adolescent Psychology: Translating Research into Practice in Lawrence, KS.

Gorodzinsky, A.Y., Davies, W.H. \& Hendrickson, K. (2007, April). Parents' perceived risk of and preparation for avian influenza pandemic. Poster presented at the Great Lakes Regional Conference on Child Health, Cincinnati, OH. and at the Wisconsin Psychological Association Conference, Middleton, WI.

Davies, W.H., Gorodzinsky, A.Y. \& Hendrickson, K. (2007, April). Parents' Sources of Information about Pandemic Influenza: Associations with Adherence to Federal Preparation Guidelines. Poster presented at the Great Lakes Regional Conference on Child Health, Cincinnati, OH.

Teaching Experience

Spring 2011

Fall 2010

Spring 2008

Fall 2007

Spring 2007

Guest Lecturer

Spring 2012 Child Psychology lectures: infant emotional and personality development and suicide prevalence and prevention University of Wisconsin-Milwaukee, Milwaukee, WI

Spring 2011 Introduction to Personality lecture about biological theories of personality University of Wisconsin-Milwaukee, Milwaukee, WI

Fall $2010 \quad$ Introduction to Psychology lecture about health psychology University of Wisconsin-Milwaukee, Milwaukee, WI 
Spring 2010 Introduction to Psychology lecture about psychotherapy Mount Mary College, Milwaukee, WI

Spring 2009 Relationships between chronic illness and sibling relationships University of Wisconsin-Milwaukee, Milwaukee, WI

Fall 2008 Relationships between chronic illness and sibling relationships University of Wisconsin-Milwaukee, Milwaukee, WI

Fall 2007 Introduction to Psychology lecture about intelligence University of Wisconsin-Milwaukee, Milwaukee, WI

Professional Affiliations

August 2010 to Present April 2009 to Present Trainee member, IASP and IASP SIG - Pain in Childhood January 2007 to Present Student member, APA Student member, Society of Health Psychology Division 38 of APA

January 2007 to Present

August 2006 to 2013

Student member, Society of Pediatric Psychology Division 54 of APA

Member, Association for Graduate Students in Psychology (AGSIP) at University of Wisconsin-Milwaukee, Milwaukee, WI

May 2008 to 2012

Founding member, Health Psychology Graduate Students' Club at University of Wisconsin-Milwaukee, Milwaukee, WI. President from May 2008 to May 2011 